\title{
Can Nature-Based Solutions Deliver a Win-Win for Biodiversity and Climate Change Adaptation?
}

\author{
Isabel Key ${ }^{1,2}$, Alison Smith ${ }^{1,3}$, Beth Turner ${ }^{1,4}$, Alexandre Chausson ${ }^{1}$, Cécile Girardin ${ }^{1,3}$, \\ Megan Macgillivray ${ }^{1}$, Nathalie Seddon ${ }^{1 *}$
}

1. Nature-based Solutions Initiative, Department of Zoology, University of Oxford, Oxford, UK

2. Changing Oceans Research Group, School of GeoSciences, University of Edinburgh, Edinburgh, UK

3. Environmental Change Institute, School of Geography and Environment, University of Oxford, Oxford, UK

4. Centre d'Étude de la Forêt, Département Des Sciences Biologiques, Université Du Québec à Montréal, Montréal, QC, Canada

${ }^{*}$ Correspondence Nathalie Seddon, Nature-based Solutions Initiative, Department of Zoology, University of Oxford, Oxford, UK.

Email: nathalie.seddon@zoo.ox.ac.uk

Keywords: Nature-based solutions; Climate change adaptation; Biodiversity; Ecosystembased adaptation

\begin{abstract}
Nature-based solutions (NbS) are increasingly recognised for their potential to address both the climate and biodiversity crises. These outcomes are interdependent, and both rely on the capacity of $\mathrm{NbS}$ to support and enhance the health of an ecosystem: its biodiversity, the condition of its abiotic and biotic elements, and its capacity to function normally despite environmental change. However, while understanding of ecosystem health outcomes of nature-based interventions for climate change mitigation is growing, the outcomes of those implemented for adaptation remain poorly understood with evidence scattered across multiple disciplines. To address this, we conducted a systematic review of the outcomes of 109 nature-based interventions for climate change adaptation using 33 indicators of ecosystem health across eight broad categories (e.g. diversity, biomass, ecosystem functioning and population dynamics). We showed that $88 \%$ of interventions with positive outcomes for climate change adaptation also reported measurable benefits for ecosystem health. We also showed that interventions were associated with a $67 \%$ average increase in local species richness. All eight studies that reported benefits in terms of both climate change mitigation and adaptation also supported ecosystem health, leading to a triple win. However, there were also trade-offs, mainly for forest management and creation of novel ecosystems such as monoculture plantations of non-native species. Our review highlights two major limitations of research to date. First, only a limited selection of metrics are used to assess ecosystem health and these rarely include key aspects such as functional diversity and habitat connectivity. Second, taxonomic coverage is poor: $67 \%$ of outcomes assessed only plants and $57 \%$ did not distinguish between native and non-native species. Future research addressing these issues will allow the
\end{abstract}


design and adaptive management of $\mathrm{NbS}$ to support healthy and resilient ecosystems, and thereby enhance their effectiveness for meeting both climate and biodiversity targets.

\section{1|.INTRODUCTION}

Nature-based solutions ( $\mathrm{NbS}$ ) - actions that involve working with nature to address societal challenges, with benefits for both people and biodiversity - are widely recognised as having the potential to provide a win-win for jointly addressing the climate and biodiversity crises (Austin et al. 2021; IUCN 2020; Mori et al. 2021; Seddon et al. 2021). Restoring, connecting and protecting a wide range of ecosystems and sustainably managing working lands can help reduce emissions and enhance sinks of greenhouse gases (Girardin et al. 2021) while also reducing the vulnerability of socialecological systems to the impacts of climate change (Chausson, Turner et al., 2020; Roe, Turner, Chausson, Hemmerle, \& Seddon, 2021; Seddon et al., 2020). Such actions also sustain biodiversity both directly, by protecting and enhancing ecosystems and the species they support, and indirectly by reducing climate change and its impacts on ecosystems. Recognising the interlinked nature of these two global challenges, the first ever joint report from the intergovernmental panels on climate change and biodiversity highlighted the need for a paradigm shift towards addressing the 'simultaneous objectives of a habitable climate, self-sustaining biodiversity, and a good quality of life for all' across multifunctional landscapes, including prominent use of nature-based solutions (IPBES-IPCC, 2021).

For $\mathrm{NbS}$ to sustain the delivery of societal benefits in the long term, they need to support and enhance healthy ecosystems that are resilient in the face of environmental change (IUCN 2020; Seddon et al. 2021). The health of an ecosystem, including its capacity to resist and recover from environmental shocks and change, depends on a wide range of factors. These include both biotic and abiotic factors, in particular the diversity, abundance and composition of its component species, the condition of its soils and water, the effective functioning of supporting processes such as carbon, water and nutrient cycling, reproduction and growth and its connections to other ecosystems (Oliver et al., 2015a). Ecosystem health is thus defined as the condition of an ecosystem in which these biotic and abiotic dynamic attributes are expressed within the normal ranges of activity relative to its ecological state of development (SER, 2004). A healthy ecosystem is one with biodiversity and species composition similar to that of a reference or baseline ecosystem, good water, soil and air quality, key ecosystem functions intact, and resilience to environmental change.

Biodiversity is a fundamental component of ecosystem health (for definitions see Table 1). More biodiverse ecosystems often support a greater provision of ecosystem services in the short term, such as when niche complementarity leads to increased biomass production and carbon storage (Mori et al. 2021; Qiu and Cardinale 2020), as well as greater resilience to change in the longer term. Ecosystems with more species tend to be able to sustain productivity in the face of perturbations, such as those caused by climate change, through increased functional redundancy and adaptive capacity (Oliver et al., 2015b). The effect of the interdependent relationship between biodiversity and carbon sequestration has recently been estimated at a global 
scale: reducing greenhouse gas emissions could help maintain global tree diversity, in turn avoiding a $9-39 \%$ drop in primary productivity on land over half a century and the associated emissions (Mori et al. 2021).

There has been widespread interest in using nature to address societal challenges in recent years, such as through planting trees to offset carbon emissions, but not all of these interventions meet the standards for an action to be defined as an $\mathrm{NbS}$, including delivering measurable benefits for biodiversity and being implemented by or in partnership with local communities (IUCN 2020; Seddon et al. 2021). Data on the outcomes of nature-based interventions for ecosystem health are not always collected, and existing analysis has focussed on synergies between biodiversity and climate change mitigation goals using broadscale mapping or scenario modelling approaches (De Lamo et al. 2020; Strassburg et al. 2020), while the potential synergies or trade-offs with climate change adaptation goals remain largely unreported. This lack of attention to ecosystem health outcomes is problematic because it could lead to nature-based interventions that fail to deliver benefits for biodiversity, and are consequently not resilient to climate change in the long term. For example, there is concern that funding through carbon credits has encouraged creation of fast-growing, single-species tree plantations that sequester carbon rapidly in the short term, but have low resilience as a carbon store, miss opportunities to support biodiversity, and sometimes lead to water shortages (Heilmayr, Echeverría, and Lambin 2020; Lewis et al. 2019; Scheidel and Work 2018). Such interventions may be mis-labelled as NbS, but NbS would be designed to deliver multiple benefits for local communities and to support or enhance ecosystem health, in line with the latest evidence and guidelines, including taking a long-term, holistic approach to evaluating outcomes (Chazdon 2020; Fischer et al. 2021; IUCN 2020; Welden, Chausson, and Melanidis 2021). Good design can also avoid or minimise trade-offs, such as by using a greater diversity of species, choosing native species, and setting targets to maximise long-term rather than short-term carbon storage (Chausson et al. 2020; Girardin et al. 2021; Seddon, Chausson, et al. 2020).

Designing $\mathrm{NbS}$ that deliver multiple benefits for people and nature in the long term requires information on how to maximise ecosystem health. However, there is no comprehensive overview of the evidence on the outcomes of $\mathrm{NbS}$ for ecosystem health. Synergies and trade-offs between biodiversity conservation and carbon storage have recently gained attention in scientific research (modelling studies e.g. Sala \& Giakoumi (2018), and empirical evidence e.g. Osuri et al. (2020)), but interactions with outcomes for climate change adaptation have received less attention, and synthesis across empirical studies is lacking. A review of the outcomes of naturebased interventions for climate change adaptation by Chausson, Turner et al. (2020) recorded information on the overall ecological outcomes of interventions, but did not record individual ecosystem health metrics. There are also numerous reviews of the ecosystem health outcomes of specific types of conservation interventions, such as for terrestrial protected areas (e.g. Gray et al., 2016, Geldmann et al., 2018), marine protected areas (e.g. Sala \& Giakoumi 2018), plantation forestry (e.g. Bremer \& Farley, 2010) and natural forest regeneration (e.g. Uebel, Wilson \& Shoo, 2017); some of these will have also contributed to climate change adaptation or mitigation but they 
were not designed as climate $\mathrm{NbS}$ and therefore do not provide evidence on both climate and ecosystem health outcomes.

In summary, there are three key evidence gaps; there has been no systematic assessment of (1) the outcomes of nature-based interventions to address climate change adaptation for the health of ecosystems, including their diversity, functioning, and connectivity; (2) the extent to which outcomes vary depending on metrics used to assess ecosystem health and/or the ecological context of the nature-based interventions (i.e. the type of intervention and the ecosystem in which it is implemented); and (3) whether and how nature-based interventions can both reduce climate change impacts and support ecosystem health. We address these evidence gaps by collating evidence on the outcomes of nature-based interventions for ecosystem health, and how these relate to outcomes for climate change adaptation. We use systematic coding of studies and meta-analytical methods to answer six research questions (RQ): RQ1: What is the geographical distribution and typology of nature-based interventions that have evidence on both climate change adaptation and ecosystem health outcomes? RQ2: How are outcomes for ecosystem health measured? RQ3: Do nature-based interventions for climate change adaptation support ecosystem health? RQ4: Do outcomes vary depending on the methods used to measure ecosystem health? RQ5: Do outcomes vary with ecological context of the nature-based intervention (where ecological context refers to the type of intervention, the ecosystem in which it is implemented and the time since implementation)? RQ6: Can nature-based interventions support both ecosystem health and address climate change, and how does that vary with the aspects of ecosystem health assessed?

We use a meta-analysis of outcomes for species richness - a commonly used indicator of biodiversity - to address RQ3, and predict that changes in species richness will be greater for interventions that have been in place longer, and for interventions involving restoration and creation, rather than protection and management, due to the control or baseline sites likely being degraded. We also predict that there will be more negative or mixed ecosystem health outcomes for interventions involving creation of novel ecosystems, and when more taxa and more categories of metric are studied for a single intervention. We discuss the comprehensiveness and quality of the evidence for ecosystem health outcomes of $\mathrm{NbS}$, and the ability of $\mathrm{NbS}$ to deliver a win-win for climate and biodiversity, before outlining the implications of these findings for the spheres of research, practice and policy. Through this synthesis we aim to inform the design of resilient nature-based solutions which better support ecosystem health, and creation of policies that maximise synergies between biodiversity conservation and climate action.

\section{MATERIALS AND METHODS}

\section{1 | Definitions}

Due to variation in the use of some social and ecological terms within research, practice and policy literature, we provide definitions for the key terms we use in this review (Table 1). We formulated our own hierarchy to describe the ecosystem health outcomes of interventions (Table 2). At the lowest level of the hierarchy are the 
individual ecosystem health metrics (e.g. Shannon's diversity index). These are grouped into metric types (e.g. species diversity), derived from a draft list compiled before the review which was then revised through an inductive process whilst coding the studies. The metric types are grouped into broad metric categories (e.g. diversity). The broad categories were chosen to reflect the types of metrics we found across the interventions, rather than 'forcing' our dataset into categories defined elsewhere, although we drew on the framework developed by Smith et al. (2017). We have assigned each ecosystem health metric to just one broad category, to aid data analysis, although some metrics could be placed in multiple categories (Table 2 footnotes). Each intervention was then assigned an overall ecosystem health assessment (e.g. an increase in ecosystem health), which was comprised of one or more individual ecosystem health outcomes (e.g. an increase in Shannon's diversity index for plants and an increase in oak canopy cover).

\section{2 | Data collection}

Our review builds on a global systematic map of nature-based interventions in any ecosystem, except urban and agricultural, which had at least one reported effect on a climate change or hydrometeorological impact (Chausson, Turner et al., 2020). The map was based on a systematic search of academic literature up to April 2018, aimed at extracting evidence on the outcomes of nature-based interventions for adapting to climate change, although any evidence on climate mitigation was also recorded. Overall intervention effects on ecosystem health were also recorded, but were not explored in depth; nor was the quality of this evidence documented. This systematic mapping and coding protocol was later extended to papers published up until April 2020, this time only for interventions in low and lower-middle income countries, for a review of local development outcomes from nature-based interventions (Roe et al. 2021). The data for both studies are available online on the Nature-based Solutions Initiative's Evidence Tool (www.naturebasedsolutionsevidence.info/evidence-tool/). For our review, we used the subset of these studies that reported outcomes for ecosystem health. All the studies in our review therefore contain empirical evidence on the outcomes of interventions for both impacts of climate change (referred to hereafter as climate change adaptation outcomes) and ecosystem health, and the subset of these interventions which had beneficial outcomes for both could be effective nature-based solutions for climate change adaptation. Abiotic aspects of ecosystems, such as air and water quality, were only coded as ecosystem health outcomes if the authors linked these outcomes to ecosystem health. We did not conduct a separate search for interventions with outcomes for climate change mitigation and ecosystem health. This means that the only information we have on the effect of interventions on mitigation is from studies that happened to also record this information in addition to effects on adaptation.

In this review, we disaggregated ecosystem health outcomes into individual metrics, categorised as shown in Table 2. We also coded the following additional information for each metric where appropriate: kingdom of taxa studied, animal class, plant group, native/non-native identity of species, and the direction of the outcome. Each outcome was coded as positive (increase in ecosystem health metric, or combination of positive and no effect), negative (decrease in ecosystem health metric, 
or combination of negative and no effect), mixed (combination of positive and negative over space or time), no effect (no change apparent, including non-statistically significant changes, but not untested changes), or unclear (unclear effect on ecosystem health, e.g. due to lack of a control or baseline, or lack of clarity from the authors as to what constitutes an improvement in the state of the ecosystem). Direction of outcome was determined from the results and supplementary results from papers; the framing of an outcome by authors was used to determine whether a given outcome was beneficial or not for ecosystem health, and an increase in e.g. abundance of a non-native species was coded as a positive outcome unless framed as otherwise by the authors. The majority of coding was conducted by a single author, with the first six studies also being separately coded by a second author; for the full coding protocol, see S1.1. Information on the interventions themselves (e.g. intervention type, ecosystem type), the overall direction of ecosystem health outcomes (i.e. the net result across multiple ecosystem health outcomes from a single intervention), and their outcomes for climate change adaptation and mitigation, was collated from the existing systematic coding available from the Evidence Tool; for detailed methods on this coding protocol, see Chausson, Turner et al. (2020). The full dataset analysed for this study is provided in the Supplementary Information.

\subsection{Data analysis}

\subsection{1 | Outcome analysis}

We analysed the frequency and coincidence of use of different ecosystem health metrics and broad metric categories, and compared outcomes across taxa and of native vs. non-native species. Analyses of native vs. non-native species excluded ecosystem health outcomes for which the native/non-native identity of species was either not relevant to the metric (e.g. litter cover) or could be incorporated within it (e.g. habitat quality). Note that we analysed the taxonomic groups and native/non-native identity of species assessed in outcomes, rather than those used for the implementation of an intervention (S1.2). Chi-squared tests were used to assess the relationship between ecosystem health outcome direction and four variables: habitat type, intervention type, taxonomic groups studied, and the native/non-native identity of the species studied; where overall relationships were significant, post-hoc analyses were conducted (Ebbert 2019). To meet the assumptions for chi-squared tests, the dependent variable categories were grouped into two: positive or no effect (the absence of a negative effect), and negative or mixed effect (the presence of at least one negative effect), referred to hereafter as the binary outcome direction. See S1.2 for details of the independent variable categories, and assumptions of the chi-squared tests. Wilcoxon rank sum tests were used to test the relationship between binary outcome direction at the intervention level and the number of unique metrics and the number of broad metric categories used per intervention. We could not statistically test the relationship between broad metric category and outcome direction due to violating assumptions: assessing metric category use at the intervention level would result in too many groups, since one intervention could have several ecosystem health metric categories, and looking at the outcome level was not possible due to nonindependence between outcomes of the same interventions. We conducted a robustness assessment on the proportions of interventions with each outcome 
direction, by sequentially excluding different subsets of the data with weaker evidence: those with poor or absent methods, no comparator, and one, two or three broad ecosystem health metrics (S1.3). Associations of ecosystem health outcomes with those for climate change adaptation and mitigation were assessed by finding the frequency with which different outcomes co-occurred from the same intervention, discussion of individual cases, and analysis of the types of climate impacts addressed. Note that when percentages are given that do not sum to $100 \%$ this is due to there being categories with very few members that we do not report.

\subsection{2 | Species richness meta-analysis}

We performed a meta-analysis on the effects of interventions on species richness because this was the only metric that was commonly reported using consistent methods across studies, and is also a useful indicator of ecosystem functioning and broader ecosystem health (Fleishman, Noss, and Noon 2006; Qiu and Cardinale 2020). Due to the great variety of interventions, habitats, taxa and study methods included, the size of the mean effect on species richness is not necessarily meaningful or broadly applicable, therefore the aim of the meta-analysis was to determine the average direction of effect rather than the size of this effect. We used the log response ratio $(\operatorname{Ln} R)$ as the measure of effect size because it is suitable for the varied study designs and taxonomic coverage across our dataset (Spake \& Doncaster, 2017; S1.4.1). Ln $R$ was calculated as (Hedges, Gurevitch, and Curtis 1999):

$$
\operatorname{Ln} R=\ln \frac{\overline{\mathrm{x}}_{t}}{\overline{\mathrm{x}}_{c}}
$$

Where $\bar{x}_{t}$ is the sample mean species richness at the treatment site (where the intervention took place) and $\bar{x}_{c}$ is the sample mean species richness at the control or baseline site (a control site sampled at the same time as the treatment site, or a historical baseline sampled before the intervention was implemented).

We found the mean $\operatorname{Ln} R$ before taking the anti-log to find the geometric mean ratio of species richness in the treatment compared to the control or baseline, and calculated $95 \%$ confidence intervals by percentile bootstrapping using the resample $R$ package (Hesterberg, 2015). We report the unweighted results due to the lack of an appropriate weighting method for the small heterogeneous dataset, and exclude outcomes for non-native species from our final analyses due to the relationship between non-native species richness and ecosystem health being unclear (for details of sensitivity analysis see S1.4.2). The relationship between $\operatorname{Ln} R$ and the length of time for which an intervention had been implemented was tested using a Spearman's rank test. The relationship between $\operatorname{Ln} R$ and intervention type was assessed by comparing median values; statistical analysis was not appropriate due to the small number of data points for some intervention types. To see the meta-analysis coding protocol see S1.4.3. All analyses were conducted in R-4.1.0 (R Core Team, 2021). 


\section{RESULTS}

\section{1 | What is the geographical distribution and typology of nature-based interventions that have evidence on both climate change adaptation and ecosystem health outcomes? (RQ1)}

We identified 80 papers providing evidence on the outcomes of 109 interventions for both climate change adaptation and ecosystem health; 17 of the interventions also reported outcomes for climate change mitigation. The interventions took place across all continents except Antarctica, being relatively evenly spread across Asia \& Pacific, Africa, North America and Europe, but with low coverage in West Asia (5\%) and Latin America \& Caribbean (3\%) (Fig 1a). Despite this geographical bias, interventions were relatively evenly distributed across income groups, with $12 \%$ of interventions in lowincome countries (which comprise $14 \%$ of countries globally), $50 \%$ middle income ( $49 \%$ of countries globally) and $38 \%$ high income (37\% of countries globally). The interventions most commonly involved restoration (28\%) or a combination of protection, restoration and/or management (28\%); projects that involved at least in part the creation of novel habitats (e.g. planting trees where they were historically absent) made up $18 \%$ of interventions (Fig 1b). A variety of habitats were included, although there was a bias towards terrestrial habitats: $75 \%$ of interventions were entirely terrestrial, with the remaining $25 \%$ being at least partially in coastal, marine or freshwater habitats (Fig 1c). 34\% of interventions involved some type of forest, and $18 \%$ involved some type of grassland, whereas only $12 \%$ of interventions included at least some coastal or marine habitats. The studies date back over the last two decades with the earliest published in 2002 and the most recent in 2020, although more studies were from recent years.

\subsection{How are outcomes for ecosystem health measured? (RQ2)}

\subsection{1 | Ecosystem health metrics}

Biomass and diversity were the most commonly assessed broad metric categories, and the majority of studies focused on just one or two categories. The biomass category accounted for $31 \%$ of reported outcomes (Fig 2; Table S1). A third of these outcomes were measures of plant, animal or microbial biomass; just under a third focused on the density of habitat (i.e. the percentage cover of the habitat in a given area); with the remainder being measures of area of habitat, stem density, canopy cover and litter cover. The next most common broad metric category was diversity; $77 \%$ of these were measures at the taxonomic level, with fewer at the functional and habitat level, and none at the genetic level. Several aspects of ecosystem functioning and population dynamics were examined, comprising $19 \%$ of outcomes, with age structure and functional identity the most common. $16 \%$ of outcomes involved evaluation of an aspect of ecosystem composition; $2 \%$ were for an unspecified aspect of ecosystem health or biodiversity, usually from stakeholder interviews and workshops. The least common metrics were habitat quality, landscape structure (i.e. connectivity and fragmentation) and conservation status. It is noteworthy that two ecosystem health metrics that were defined a priori were not used in any of the studies: phylogenetic diversity and genetic diversity. 
$31 \%$ of interventions had their outcomes reported with a single ecosystem health metric, and $28 \%$ reported only two ecosystem health metrics (Fig 1d). Looking at the broad metric category level, $36 \%$ of interventions only had metrics from a single category, 35\% covered two categories, and only one intervention covered five categories (out of the total of eight) (Fig 1e). The most common category to be reported alone was ecosystem functioning and population dynamics (46\%) followed by biomass $(21 \%)$, and the most common categories to be reported together were biomass and diversity ( $26 \%$ of those with two categories; for more details see S4.1).

\subsection{2 | Taxonomic coverage and identification of native species}

Ecosystem health assessments were strongly skewed towards plants and ecosystem components located above ground at both the outcome and intervention levels (see S4.2). For example, we found that $67 \%$ of outcomes assessed plants, $9 \%$ assessed plants alongside at least one other ecosystem component, $15 \%$ assessed animals, and $4 \%$ assessed fungi or microorganisms. Of the outcomes for plants, $28 \%$ were for trees alongside grasses and/or other plants, $16 \%$ were for grasses alongside other plants, and $14 \%$ were for tree species alone. For animals there was a bias towards invertebrates (56\% compared to $30 \%$ fish, $22 \%$ birds and $16 \%$ mammals). Across all these outcomes, $76 \%$ assessed only above-ground components, $15 \%$ aquatic and $5 \%$ soil. $5 \%$ of outcomes incorporated a non-living component of the ecosystem, such as litter cover, surface accretion, soil carbon, water body structure and water quality.

Only $15 \%$ of outcomes for which it was relevant to consider native/non-native species assessed native species (S4.2); $24 \%$ assessed a mixture of native and nonnative species; and $2 \%$ assessed non-native species alone. $3 \%$ assessed the status of species that had been moved outside their natural range within their country of origin, and one outcome assessed the status of a native species that had become over-dominant. However, for most outcomes (57\%), it was unclear whether the species assessed were native or non-native; $58 \%$ of interventions had at least one ecosystem health outcome where it was unclear whether the species studied were native or non-native.

\section{3 |Ecosystem health outcomes}

\subsubsection{Do nature-based interventions for adaptation support ecosystem health? (RQ3) \\ Overall effects}

Most interventions (72\%) were reported to have positive ecosystem health outcomes overall, i.e. for the ecosystem health metrics used for these interventions only positive effects, or a combination of positive and unclear/no effect, were reported. $12 \%$ of interventions reported a mixture of positive and negative outcomes for ecosystem health, $4 \%$ were entirely negative, $9 \%$ unclear and $3 \%$ reported no effect. Examples of ecosystem health outcomes from a sample of interventions with positive overall outcomes are shown in Table 3. Although only $4 \%$ of interventions reported solely negative ecosystem health outcomes, $16 \%$ had at least one negative outcome (see examples in Table 4). Our robustness assessment revealed that the proportion of interventions with positive outcomes decreased with the application of increasingly 
stringent evidence quality criteria (Table S2). When looking at only the most robust studies (those with strong methods, a comparator, and more than two broad metric categories) $51 \%$ of outcomes were positive and $30 \%$ mixed across 27 interventions, compared to $72 \%$ and $12 \%$ when all 109 interventions were included.

\section{Effects on species richness}

We identified 34 interventions (across 24 papers) that reported effects on species richness; 25 of these (across 19 papers) had sufficient data for inclusion in the metaanalysis. The interventions in this subset were primarily in terrestrial habitats most commonly involving restoration or a combination of approaches; the majority (90\%) of species richness measures were for plants (Table S3). The mean change in species richness was a 1.67-fold increase between the treatment and control or baseline $(95 \%$ confidence interval: 1.05-2.65) (Fig 5). This is a conservative estimate which is not weighted, and excludes non-native species and effect sizes with zero values for the control/baseline. Our sensitivity analysis showed that weighting by study design and sample size, adjusting for zero values, and excluding response ratios for non-native species, did not change the direction of the mean effect size (S1.4.2).

Log response ratio was not significantly related to the time for which the intervention had been in place (Rho $=-0.12, p=0.51$ ). The median $\operatorname{Ln} R$ was highest for interventions involving at least some creation of novel habitat (median $\operatorname{Ln} R=2.74$, $\mathrm{n}=9$ ), followed by restoration interventions (median $\operatorname{Ln} R=1.22, \mathrm{n}=18$ ) and those involving a combination of restoration, protection and/or management (median $\operatorname{Ln} R=$ $0.71, \mathrm{n}=10)$. Only one intervention involved solely protection $(\operatorname{Ln} R=0.08)$, and management interventions had a median negative effect size (median $=-0.36, n=4)$. Interventions which had highly degraded pre-intervention states resulted in larger species richness effect sizes; the six greatest effect sizes all reported none or very few species present in the control or baseline state. The greatest reported proportional increase was a 56-fold increase (from a mean of 0.5 to 28) in freshwater benthic macroinvertebrate species richness from the rehabilitation of a creek in China through installation of check dams, guiding dikes and reforestation with non-native species (Yu et al. 2012). The next five highest response ratios were for different types of erosion barriers designed to restore degraded rangeland in Kenya, which each led to an increase in plant species richness from zero to 19-25 (Kimiti, Riginos, and Belnap 2017). There were eight negative effects on species richness reported (across six interventions).

\subsection{2 | Do outcomes vary with the method used to measure ecosystem health? (RQ4)}

For broad metric categories where at least ten outcomes were recorded across interventions (a threshold set to avoid drawing false conclusions from small sample sizes), the category with the highest proportion of positive outcomes was habitat quality, followed by biomass, then diversity (Fig 3). The highest proportion of negative or mixed outcomes were jointly from diversity and ecosystem functioning/population dynamics outcomes, followed by habitat quality and ecosystem composition. Measures of diversity had by far the highest proportion of outcomes with no effect; this 
included four interventions where there was a positive effect on a biomass metric but no change for the diversity metric.

Overall ecosystem health assessments using a greater number of broad metric categories were significantly more likely to be negative or mixed, than positive or no effect ( $\mathrm{W}=964, p=0.01$; Fig S1a). This trend weakened when looking at the number of unique metrics rather than broad categories per intervention $(W=888.5, p=0.07$; Fig S1b). Binary outcome direction at the intervention level also varied significantly with the taxonomic group studied $\left(X^{2}=11.9, p=0.018\right)$. Interventions reporting outcomes for both plants and animals had significantly more negative or mixed effects (residual $=-3.37, p=0.007$ ), than those that reported on only plants, only animals, or a combination of plants, animals and other living or non-living components of the ecosystem.

\subsection{3 | Do outcomes vary with the ecological context of the nature-based intervention? (RQ5)}

Binary outcome direction (the presence/absence of at least one negative outcome) did not vary significantly with habitat type $\left(x^{2}=0.92, p=0.82\right)$, broad intervention type $\left(x^{2}\right.$ $=1.71, p=0.79)$, or the native or non-native/invasive composition of the species studied $\left(x^{2}=4.41, p=0.11\right)$. However, closer inspection of the data revealed some trends (Fig 4). The highest proportion of positive outcomes were reported for interventions that were a combination of created and non-created ecosystems (although the sample size was small), followed by interventions that were a combination of protection, restoration and/or management. Negative outcomes at the intervention level were restricted to created habitats and management interventions (Fig 4a), and the highest proportion of mixed or negative outcomes was for created habitats. In terms of habitat type, negative outcomes at the intervention level were restricted to forests, and the highest proportion of mixed or negative outcomes was also for forests (Fig 4b). With respect to taxonomic group, negative outcomes were restricted to interventions that had assessments of the effects on just plants, or on animals, plants and other (Fig 4c). The highest proportion of intervention level outcomes that were negative or mixed, however, was for assessments of both animals and plants. Finally, although the native or non-native identity of species was only clearly reported for $15 \%$ of relevant outcomes, the greatest proportion of negative or mixed outcomes was for interventions reporting on at least some non-native/invasive species (Fig 4d).

Of the 55 outcomes that included only native species, $73 \%$ were positive and $11 \%$ were negative or mixed. This compares to $51 \%$ positive and $14 \%$ negative or mixed across the remaining 277 ecosystem health outcomes for which species native/nonnative identity is relevant, and $25 \%$ positive and $25 \%$ negative or mixed across just the eight outcomes for which species were non-native/invasive. Overall, $16 \%$ of the 224 positive ecosystem health outcomes included at least some non-native or invasive species. For interventions involving created habitats this was higher at $25 \%$ (out of 59 ), compared to $13 \%$ (out of 165) for interventions not involving created habitats.

\section{4 | Can nature-based interventions support both ecosystem health and address climate change and how does that vary with ecological context? (RQ6)}




\subsubsection{Climate change adaptation}

Of the 79 interventions for which positive ecosystem health outcomes were reported, $59(75 \%)$ also reported positive outcomes for climate change adaptation across 19 different climate impacts (Fig 6). Meanwhile, $88 \%$ of interventions for which positive climate change adaptation outcomes were reported also reported positive outcomes for ecosystem health. Overall, we found that $54 \%$ of interventions were reported to have positive outcomes for both ecosystem health and adaptation. However, tradeoffs were also present, with six $(8 \%)$ of the interventions with positive ecosystem health outcomes overall having mixed adaptation outcomes, and four $(5 \%)$ having negative outcomes. 11 positive ecosystem health outcomes were coupled with negative climate change adaptation outcomes, and five of these were for water availability. Three of the four interventions with negative ecosystem health outcomes overall also had negative adaptation outcomes. For the interventions with negative outcomes for both ecosystem health and climate change adaptation, there were six negative climate impact outcomes overall with two being for timber production and two being for water availability. Table S4 provides specific examples of associations between ecosystem health and climate change adaptation outcomes; Table S5 gives more details on adaptation outcomes for interventions in this study with positive, negative or mixed ecosystem health outcomes.

Interventions that enhanced ecosystem functioning and population dynamics had the highest proportion of positive climate change adaptation outcomes $(96 \%$ of 25$)$ (Table 5; Fig S2). Meanwhile, interventions that increased diversity had the lowest proportion of positive adaptation outcomes (53\% of 30 ), and also the highest proportion of negative or mixed adaptation outcomes (33\% of 30 ). Interventions with positive outcomes for biomass had a similarly high proportion of outcomes with negative or mixed adaptation outcomes ( $21 \%$ of 52$)$.

\subsection{2 | Climate change mitigation}

Only $17(16 \%)$ of the interventions in this review had reported outcomes for climate change mitigation, so we were limited in the extent to which we could explore associations between ecosystem health outcomes and effects on greenhouse gas fluxes. However, of the 14 interventions with positive ecosystem health outcomes which also reported mitigation outcomes, all but one of these outcomes were positive, the other being mixed (Fig 6a). Of the three interventions with negative or mixed ecosystem health outcomes which also reported mitigation outcomes, one of these mitigation outcomes was negative, one was mixed and the last unclear. Of the 20 interventions with at least one positive outcome for species richness, only three had mitigation outcomes; two of these were positive and one unclear.

\subsection{3 | Three-way associations}

Of the 15 interventions that had reported outcomes for all three of ecosystem health, climate change adaptation and mitigation, eight (53\%) of these interventions had positive outcomes for all three; two had positive ecosystem health and mitigation outcomes but negative adaptation outcomes; and the remaining five had different combinations of positive, negative, mixed and unclear outcomes (Table S6). All of the eight interventions that reported both climate change mitigation and adaptation benefits also had reported positive outcomes for ecosystem health. In other words, of 
the 13 interventions with positive outcomes for both ecosystem health and climate change mitigation, eight (62\%) also had positive outcomes for adaptation.

\section{Discussion}

We conducted the first global, systematic review of the outcomes for ecosystem health of nature-based interventions to address the adverse impacts of climate change on people. Our main finding is that, overall, such interventions were associated with positive outcomes for ecosystem health, including increased species richness, and that most of these also brought climate change adaptation and/or mitigation benefits. However, this broad finding comes with important caveats, in particular in relation to the type of intervention and ecosystem involved, and the aspect of ecosystem health under study. Here, we discuss the main findings of the review and the strength of the evidence available, and identify opportunities for future research and implications for practice and policy.

\subsection{Synergies and trade-offs between outcomes for climate change adaptation and ecosystem health}

We found that nature-based interventions implemented to address climate change impacts in general also enhanced ecosystem health. Specifically, most (72\%) of the 109 interventions in this review were reported to have improved ecosystem health, though this fell to $51 \%$ when we excluded all but the most robust scientific studies. Positive outcomes were reported across all broad types of nature-based intervention and habitat, and most commonly involved an increase in aspects of biomass, diversity and ecosystem functioning or population dynamics. On average, interventions were associated with a large (67\%) increase in species richness (the number of plant or animal species recorded). There was evidence that nature-based interventions can enhance multiple aspects of ecosystem health, although few studies assessed several different aspects simultaneously.

Similarly, most (75\%) interventions with positive ecosystem health outcomes were also reported to have positive outcomes for climate change adaptation, most often by increasing food availability or reducing soil erosion, while studies that reported negative outcomes for ecosystem health also reported negative outcomes for adaptation. This aligns with scientific understanding that healthy ecosystems are necessary for the flow of ecosystem services to be sustained (Seddon, Smith et al. 2021). Interventions that enhanced aspects of ecosystem functioning and population dynamics were most commonly associated with positive climate change adaptation outcomes, which is in line with theory that ecosystem functioning supports the provision of ecosystem services (Sekercioglu 2010). However, we also found examples of negative and mixed outcomes for ecosystem health, especially for interventions involving management of forests and creation of novel forest ecosystems. Similarly, trade-offs between ecosystem health and climate change adaptation outcomes often involved non-native tree plantations leading to decreases in water availability (reviewed in Chausson, Turner et al., 2020b). Some negative outcomes came alongside multiple positive outcomes. For example, communitybased forestry in Nepal had positive outcomes in terms of mitigation and adaptation 
(increased carbon stocks, water quality and availability, and reduced erosion and landslide risk) and most aspects of ecosystem health (biomass, habitat extent, habitat connectivity and intactness); but the authors also reported an increase in the number of invasive plant species (Paudyal et al., 2019). These examples highlight that interventions must be carefully designed to deliver synergies and avoid trade-offs, and that multiple aspects of ecosystem health should be considered, as increases in some indicators can mask negative effects in others.

Publication bias towards positive and statistically significant results may mean that adverse outcomes could be more prevalent than our dataset suggests. However, this does not weaken the evidence showing that $\mathrm{NbS}$ can produce win-wins for ecosystem health and climate change, and these successful case studies can help to inform the design of future $\mathrm{NbS}$ projects.

\section{2 | Strength of the evidence}

Our dataset of studies encompassed a wide variety of habitats and intervention types, and differed widely in the methodologies used, and metrics and taxa studied. Here we discuss the implications of these differences for the overall findings of the review, and identify ways in which the study of ecosystem health outcomes of $\mathrm{NbS}$ can be improved.

\subsection{1 | Metrics of ecosystem health}

Most of the studies in this review only included one or two components of ecosystem health, with $36 \%$ of interventions having metrics of a single broad metric category (e.g. biomass, diversity, ecosystem composition), and $35 \%$ covering just two. No study assessed more than five out of the eight broad categories. This means that some of the interventions that were reported to have entirely positive outcomes for ecosystem health may actually have had mixed outcomes overall, but the negative effects were missed due to the failure to assess a representative suite of aspects of ecosystem health. The review provides evidence for this, since ecosystem health assessments using a greater number of broad metric categories were significantly more likely to have an overall assessment of negative or mixed. In addition, excluding interventions with fewer broad metric categories led to a higher proportion of ecosystem health outcomes being mixed. Also, some broad metric categories, such as biomass and habitat quality, were more likely to be positive, so focusing only on those categories could give a misleading picture of ecosystem health.

Within the broad ecosystem health categories used across studies, certain elements of ecosystem health gained more attention. Measures of diversity were primarily focused on taxonomic diversity, with fewer functional and habitat diversity metrics, and no genetic diversity metrics. This supports previous findings such as by Naeem et al. (2016) who found that $70-80 \%$ of studies in their review assessed only one type of diversity (from taxonomic, functional, phylogenetic or other diversity), with under $10 \%$ using three or more dimensions. We also checked for evidence gaps by crossreferencing our findings with the categories in Noss's Hierarchy of Biodiversity, which divides components of an ecosystem into three primary attributes: composition, structure and function, which are in turn subdivided into four levels: genetic, species, community and landscape (Knight, Seddon, \& Toombs, 2020; Noss, 1990). Functions 
were mainly assessed at the species level (e.g. phenology), rather than at the landscape level (e.g. nutrient cycling), community level (e.g. predation rates), or genetic level (e.g. inbreeding depression). Functional metrics generally were underrepresented, with some key aspects of ecosystem functioning never being assessed; this may be because these types of data are more difficult to collect (e.g. trait diversity) or require repeat measurements over time (e.g. primary productivity and residence time). Measures of structure were mainly focused at the community level (e.g. canopy cover), with landscape scale (e.g. connectivity), species level (e.g. age ratios) and genetic level measures (e.g. heterozygosity) being rare or absent. Composition measures were focused at the community level (e.g. species richness) and species level (e.g. abundance and biomass), with landscape measures (e.g. identity and proportions of habitats) and genetic measures (e.g. allelic diversity) being almost absent. Some of our metrics do not fit into Noss's hierarchy, including conservation status, which was only assessed once, and recovery time and ecological resistance - both components of ecological resilience - which were highly understudied, despite resilience being crucial for long-term ecosystem health especially given the rapidly changing climate.

Focusing only on biomass is likely to be a particularly problematic way of assessing ecosystem health. This was the most common metric category (33\% of outcomes), and was sometimes used as the single indicator of ecosystem health. Biomass may be popular because it is relatively easy to assess (e.g. by measuring tree diameter), but it is a crude measure because it does not distinguish between species, functions or genotypes. For example, an increase in biomass could arise from planting nonnative trees on biodiverse open habitats such as grasslands and shrubland, which would generally be expected to have a detrimental impact on ecosystem health and biodiversity conservation (Balthazar et al. 2015; Bond 2016; Bremer et al. 2010). Our study found that biomass is not necessarily associated with an increase in other ecosystem health metrics: for example, four of the 22 interventions with no effect on diversity reported a positive effect on biomass.

Species richness is also a widely used indicator for ecosystem health. Experimental and observational studies in a wide range of contexts have shown positive effects of species richness on the productivity and stability of ecosystems in variable environmental conditions (Gamfeldt et al. 2013; Isbell et al. 2015; Liang et al. 2016). Species richness has been shown to predict ecosystem functioning better than metrics of species turnover (Albrecht et al. 2021). However, measures of species richness are highly dependent on sampling effort (Chiarucci, Bacaro, Rocchini, \& Fattorini, 2008). Only two of the studies assessing species richness attempted to control for the effect of sampling effort, so most of the species richness figures reported are not true estimates of the number of species found in an area but rather measures of the density of species at a given sampling effort. Species richness only provides a minimum estimate of diversity, since it is not necessarily linearly correlated with other aspects of diversity like functional, taxonomic and structural diversity (Lyashevska and Farnsworth 2012). Moreover, an increase in species richness is not always desirable, as some ecosystems are naturally less diverse than others, and non-native or invasive species can increase species richness, so the species composition is also crucial. For 
example, prescribed burning of Mediterranean shrub led to short-term decreases in plant species richness, but also to an increase in the ratio of resprouters compared to seeders: a shift in species composition that has been shown to increase recovery rate after fires and may increase the resilience of the ecosystem and its diversity (Fuentes, Duguy, and Nadal-Sala 2018).

\subsection{2 | Taxonomic coverage and recognition of native species}

In addition to the choice of which metrics to use, evidence strength is also affected by the way in which the metrics are applied, including which taxa were studied and whether native species were distinguished from non-native species. The ecosystem health outcomes were heavily skewed towards plants, with $67 \%$ of outcomes assessing plants alone. Other taxa, including animals, fungi and microorganisms were rarely assessed, despite their critical importance in the functioning of ecosystems. This skew towards plants when assessing nature-based interventions for climate adaptation, which may relate to the role of vegetation in delivering ecosystem services and protecting from climate impacts, does not reflect global conservation monitoring programmes, which are biased towards birds (Moussy et al. 2021). Population trends in one taxonomic group are often not indicative of similar trends across other taxonomic groups (Carignan and Villard 2002; Prendergast et al. 1993); so positive outcomes for plants, for example, does not imply that there are necessarily increases in animal species (Cristescu et al. 2013; Marshall et al. 2020, 2021). For example, metrics may indicate a high quality plant community but the successful establishment of associated faunal communities depends on other factors such as the ability of fauna to disperse into the area from elsewhere (Baur 2014; Gilbert-Norton et al. 2010), and the impact of vegetation management techniques (such as thinning, mowing, burning or spraying) on fauna (Bennion et al. 2020; Humbert, Ghazoul, and Walter 2009; Prowse et al. 2017). There was a similarly strong bias towards taxa that reside above ground, with $72 \%$ of interventions only assessing effects above ground, rather than also including below ground and aquatic habitats. To understand the health of an ecosystem these elements need to be assessed in combination, since they interact to allow the ecosystem to function and produce ecosystem services. For example, soil quality affects which plant species can thrive, which will in turn affect which animals can survive, which affects the delivery of ecosystem services such as pollination (Cardoza, Harris, and Grozinger 2012; David, Storkey, and Stevens 2019; Ebeling et al. 2008).

In the majority of cases (57\% of outcomes for which it was relevant), it was unclear whether the species studied were native or non-native; this is in line with Ruaro et al.'s (2020) finding that $66 \%$ of studies of multi-metric indices of ecosystem integrity did not test or state whether they tested metrics on native or non-native species. Although a species being native does not guarantee that it is beneficial to ecosystem health, it is much more likely than for non-native species (Paolucci, Maclsaac, and Ricciardi 2013; USEPA 2016), so not knowing the composition of communities reduces the confidence in potential links between increases in metrics and increases in overall ecosystem health. Moreover, some of the positive ecosystem health outcomes reported by studies in this review were partially or entirely for non-native species; even though authors framed these outcomes as positive, in some cases this may not reflect the 
true impact on ecosystem health, such as afforestation of monocultures of non-native species.

\subsection{3 | Study timelines and baselines}

The time over which the effect of an intervention is studied can determine the size and direction of the outcome recorded. Positive or negative effects of an intervention on ecosystem health may take time to accrue, hence monitoring the outcomes of projects over the long term is of great importance. Our meta-analysis found no significant relationship between the time for which an intervention had been in place before a species richness outcome was recorded and the size of the effect on species richness; this may be due to the highly heterogeneous but small dataset, meaning the changes in species richness may have been more affected by the taxa, habitat and intervention studied. However, the effects of study timeline were apparent from individual cases. For example, transient decreases in biodiversity may be a necessary step to increase long-term resilience of a community and safeguard biodiversity into the future, as demonstrated by Fuentes et al. (2017, see 4.1.2); and Biel et al. (2017) suggest that the two years since implementation was not enough time to allow for seed dispersal and recovery of endemic plant species composition.

When comparing the size of benefits for ecosystem health between interventions, it is crucial to consider a baseline - the state of the ecosystem before the intervention was initiated. Interventions involving restoration of degraded habitat or creation of novel habitat will likely start with lower baseline values for all aspects of ecosystem health than protection or management interventions, meaning they may result in greater increases in outcome metrics, as confirmed by our analysis which found greater increases in species richness for restoration and creation interventions. However, this does not mean that restoration and creation interventions are more valuable for ecosystem health than other approaches, since the level of diversity of a restored or created ecosystem may still be lower than that of a protected or managed ecosystem. Indeed, there is evidence from our review that created habitats interventions have in practice led to the most mixed and negative effects on ecosystem health (across all broad metric categories).

\section{3 | Implications for research, practice and policy}

Here we show how the findings of our review can be applied to inform future research, practice and policy, to support the scaling up of high quality $\mathrm{NbS}$ with measurable benefits for both biodiversity and climate.

\subsection{1 | Research}

Our review has highlighted the need for researchers to consider a broader range of metrics when assessing the ecosystem health outcomes of nature-based interventions. Metrics should cover a range of aspects of ecosystem health, including abiotic elements such as soil health and biotic aspects including - where possible compositional, structural and functional measures at the genetic, species, community and landscape level, as detailed by Knight et al. (2020). This is supported by Lyashevska and Farnsworth (2012) who showed that three indices can reasonably approximate biodiversity. It is also important to ensure good taxonomic and trophic coverage, as well as considering whether species are suitable for the location, 
including whether they may be invasive and whether they will be resilient to future changes in climate. More standardised research methods, such as controlling for sampling effort in species richness measurements, would facilitate comparison of results across studies. Further systematic reviews could advance knowledge by conducting meta-analyses on specific metrics and by expanding literature searches to include urban and agricultural habitats, grey literature, and studies not published in English. Such research is key if we are to better understand the contexts (e.g. intervention methods, timeframes, spatial scales) which produce win-wins for biodiversity and climate goals in the long term. Furthermore, a better understanding of the ecosystem health outcomes of nature-based interventions and how they relate to the provision of climate change benefits, would help raise awareness that biodiversity conservation is not a 'co-benefit' of a $\mathrm{NbS}$, but rather a fundamental property that secures their effectiveness and resilience (Mori et al. 2021; Seddon et al. 2021). This would in turn increase inclusion of specific biodiversity targets in climate and development planning and help mobilise new financing streams for $\mathrm{NbS}$.

Researchers also have a crucial role to play in supporting practitioners in project design, monitoring and evaluation. Targeted research can help practitioners make decisions as to how to implement $\mathrm{NbS}$ so that they support healthy, resilient ecosystems which will continue to provide climate benefits into the future. Researchers can also develop methods of monitoring and evaluation which are better at estimating ecosystem health but are also affordable, time-efficient, and practical to implement. Remote sensing is one area in which rapid advances are aiding efficient data collection, such as analysis of satellite, drone and LiDAR imagery for granular, noninvasive assessment of ecosystem health.

\subsection{2 | Practice}

Few interventions in this review demonstrated benefits across multiple aspects of ecosystem health, and there is therefore a risk that some interventions may not be resilient in the long term and may not deliver their potential benefits for biodiversity. It is important that $\mathrm{NbS}$ are designed from the outset to deliver measurable benefits for biodiversity and ecosystem health, including benefits for a wide range of taxa, and maximising the use of native species of local provenance, tailored to the local socialecological context. Guidelines such as the IUCN Global Standard for NbS (IUCN 2020) and habitat and intervention-specific guidelines (e.g. for seagrass restoration UNEP/WIOMSA, 2020) can help practitioners ensure that biodiversity is properly incorporated into planning, monitoring and evaluation. To achieve this, practitioners can work closely with ecologists, and seek the latest evidence for implementation methods that are most likely to produce win-wins for biodiversity and climate goals using resources such as Conservation Evidence (conservationevidence.com) and the Nature-based Solutions Evidence Tool (naturebasedsolutionsevidence.info). However, since the published evidence base cannot cover every context, it is crucial that project planning also draws on local knowledge.

Forming partnerships with researchers could help practitioners with limited time and resources to monitor a wider range of ecosystem health metrics. This could also help practitioners to adopt an adaptive and experimental approach. For example, Kimiti et al. (2017) used an experimental approach to test the ecosystem health outcomes of 
five different types of erosion barriers for the restoration of degraded rangeland in Kenya.

Careful evidence-based design of NbS can also help practitioners to minimise tradeoffs between ecosystem health and other outcomes. This is easier if the opposing outcomes have different drivers, so that the negative outcome can be addressed without affecting the positive outcome. For example, Biel et al. (2017) found that removing invasive beach-grass increased the productivity of a protected bird species but also reduced coastal protection, but this trade-off could be avoided by removing beach-grass on wide, shallow areas of beach where the effect on coastal protection was lower. Testing how outcomes vary between sites and in different contexts could therefore help to minimise trade-offs.

\subsection{3 | Policy}

We have shown that NbS hold great potential as a means to deliver biodiversity conservation while tackling climate challenges, but for this potential to be fully realised reforms are required across national and international policy. Firstly, policies are needed to ensure that ecosystem health is prioritised in NbS design and implementation. For example, although $66 \%$ of signatories to the Paris Agreement included $\mathrm{NbS}$ in the adaptation and/or mitigation components of their first Nationally Determined Contributions (NDCs), most of these emphasised forest interventions, often in the context of afforestation rather than protection and restoration of a diverse range of native ecosystems (Seddon, Daniels, et al. 2020). Preliminary analyses of the second iteration of NDCs indicate that while NbS are more commonly mentioned, the focus is still on forests and targets are primarily area-based (Bakhtary, Haupt, and Elbrecht 2021). Therefore, much more work is needed to ensure national climate ambition is enhanced with robust, sustainable NbS. Strong biodiversity targets and safeguards should be included in these policy documents and a wide range of ecosystem health metrics should be monitored during the implementation of such commitments, rather than using simplistic targets such as forest extent and measuring single benefits such as carbon storage. This reflects a wider need for impacts on biodiversity to be considered as a central component of climate change policy.

There is also the need to incentivise creation of high quality NbS that improve ecosystem health and support biodiversity and good ecosystem stewardship. In the UK, for example, there are many opportunities for policymakers to support the scaling up of high quality NbS for climate change adaptation, such as through closer integration of agri-environment schemes and nature recovery strategies (Smith and Chausson 2021).

Equally, biodiversity conservation policies should consider the potential to deliver wider societal benefits including for climate change mitigation and adaptation, and recognise $\mathrm{NbS}$ as a powerful land use strategy that can reconcile competing demands for use of space and natural resources. There are signs that this is starting to happen at an international level. Although the first official draft of the post-2020 global biodiversity framework does not mention NbS explicitly, preferring the term 'ecosystem approach' for which the Convention on Biological Diversity has a formal definition (CBD, 2000), it does include one target on climate change: to 'minimize the impact of 
climate change on biodiversity, contribute to mitigation and adaptation through ecosystem-based approaches, contributing at least $10 \mathrm{GtCO} 2 \mathrm{e}$ per year to global mitigation efforts, and ensure that all mitigation and adaptation efforts avoid negative impacts on biodiversity.' Nonetheless, it is important to recognise that there remains a role for protection, restoration and management of land for the sole or primary purpose of biodiversity conservation, for example, when protecting the habitat of an endangered species (IPBES-IPCC, 2021; e.g. Biel et al., 2017; López-Bao et al. 2018).

However, in order to address global biodiversity loss and climate change, NbS and biodiversity conservation must occur alongside transformational change across sectors to address the indirect, ultimate drivers of loss (Leclère et al. 2020). Crucially, this includes dramatically cutting greenhouse gas emissions by transitioning to renewable energy sources and defunding fossil fuel projects, altering farming and manufacturing processes and eliminating subsidises for high-emitting agricultural practices (especially livestock production), eliminating environmental harm from supply chains, and changing human behaviour and consumption patterns in countries with high emissions per capita (Allwood et al. 2019; IPCC 2018b; Poore and Nemecek 2018). Without such changes, the consequent continued increase in global average temperatures will continue to accelerate biodiversity loss through increased frequency and intensity of extreme weather events, sea level rise and other impacts of climate change (IPBES-IPCC, 2021).

\section{CONCLUSIONS}

Nature-based solutions (NbS) by definition should help address societal challenges, including adapting to and mitigating climate change, whilst simultaneously supporting the health and biodiversity of ecosystems (Seddon, Smith et al. 2021). However, for $\mathrm{NbS}$ to realise their full potential, the research, practice and policy communities need to work together to improve the design, monitoring and adaptive management of $\mathrm{NbS}$ so that they deliver clear benefits for biodiversity and ecosystem health. Our systematic review has shown that there is a clear need to assess a broader range of ecosystem health metrics across a greater range of taxa, and to take into account whether species are native to an area and whether ecosystems will be resilient to future environmental change. Researchers can provide improved evidence, tools and methods to facilitate improved design and monitoring across a representative suite of metrics; practitioners can work with ecologists and local communities to ensure that both ecosystem health and societal outcomes are built into project design from the start, taking account of local ecological knowledge; policymakers can ensure that nature-based climate policy always supports ecosystem health, and biodiversity conservation explores opportunities to delivers on climate goals; and funders can support more research and monitoring of ecosystem health as well as directing investments towards well-designed projects that meet the IUCN Global Standard. These actions will enable scaling up of carefully designed and adaptively managed $\mathrm{NbS}$ that deliver multiple benefits for climate and biodiversity, while avoiding tradeoffs. 


\section{ACKNOWLEDGEMENTS}

This study was supported by a Natural Environmental Research Council Knowledge Exchange Fellowship to N. Seddon, with additional funding from the Waterloo Foundation and the University of Oxford (Oxford Martin School).

\section{DATA AVAILABILITY STATEMENT}

The data that support the findings of this study are openly available in the Supporting Information and on the Nature-based Solutions Evidence platform, www.naturebasedsolutionsevidence.info. 


\section{REFERENCES}

Albrecht, Jörg et al. 2021. "Species Richness Is More Important for Ecosystem Functioning than Species Turnover along an Elevational Gradient." Nature Ecology \& Evolution 2021: 1-12. https://www.nature.com/articles/s41559-02101550-9 (September 30, 2021).

Allwood, J.M. et al. 2019. "Absolute Zero: Delivering the UK's Climate Change Commitment with Incremental Changes to Today's Technologies." : 31. https://ukfires.org/absolute-zero/ (October 13, 2021).

Austin, W. et al. 2021. Nature-Based Solutions for Climate Change, People and Biodiversity. https://www.gla.ac.uk/media/Media_790171_smxx.pdf (September 30, 2021).

Avolio, Meghan L., Jeremy M. Beaulieu, Eugenia Y.Y. Lo, and Melinda D. Smith. 2012. "Measuring Genetic Diversity in Ecological Studies." Plant Ecology 213(7): 110515.

Bakhtary, Haseeb, Franziska Haupt, and Jana Elbrecht. 2021. NDCs - a Force for Nature?

https://wwfint.awsassets.panda.org/downloads/wwf_uk_ndcs_a_force_for_natur e_3rd_edition.pdf (October 15, 2021).

Balthazar, Vincent, Veerle Vanacker, Armando Molina, and Eric F. Lambin. 2015. "Impacts of Forest Cover Change on Ecosystem Services in High Andean Mountains." Ecological Indicators 48: 63-75. http://dx.doi.org/10.1016/j.ecolind.2014.07.043.

Baur, Bruno. 2014. "Dispersal-Limited Species - A Challenge for Ecological Restoration." Basic and Applied Ecology 15(7): 559-64.

Bennion, Leland D., Jannette A. Ferguson, Leslie F. New, and Cheryl B. Schultz. 2020. "Community-Level Effects of Herbicide-Based Restoration Treatments: Structural Benefits but at What Cost?" Restoration Ecology 28(3): 553-63. https://onlinelibrary.wiley.com/doi/full/10.1111/rec.13118 (October 13, 2021).

Biel, Reuben G. et al. 2017. "Coastal Protection and Conservation on Sandy Beaches and Dunes: Context-Dependent Tradeoffs in Ecosystem Service Supply." Ecosphere 8(4).

Bond, William J. 2016. "Ancient Grasslands at Risk." Science 351(6269): 120-22.

Bremer, Leah L, Kathleen A Farley, L L Bremer, and K A Farley. 2010. "Does Plantation Forestry Restore Biodiversity or Create Green Deserts? A Synthesis of the Effects of Land-Use Transitions on Plant Species Richness." Biodivers Conserv 19: 3893-3915.

Cao, Shixiong, Li Chen, and Xinxiao Yu. 2009. "Impact of China's Grain for Green Project on the Landscape of Vulnerable Arid and Semi-Arid Agricultural Regions: A Case Study in Northern Shaanxi Province." Journal of Applied Ecology 46(3): 536-43.

Cardoza, Yasmin J., Gabriel K. Harris, and Christina M. Grozinger. 2012. "Effects of Soil Quality Enhancement on Pollinator-Plant Interactions." Psyche (London). 
Carignan, Vincent, and Marc-André Villard. 2002. "Selecting Indicator Species to Monitor Ecological Integrity: A Review." Environmental Monitoring and Assessment 2002 78:1 78(1): https://link.springer.com/article/10.1023/A:1016136723584 (October 3, 2021).

Chausson, Alexandre et al. 2020. "Mapping the Effectiveness of Nature-Based Solutions for Climate Change Adaptation." Global Change Biology (June): 1-22.

Chazdon, Robin L. 2020. "Creating a Culture of Caretaking through Restoring Ecosystems and Landscapes." One Earth 3(6): 653-56.

Chiarucci, A., G. Bacaro, D. Rocchini, and L. Fattorini. 2008. "Discovering and Rediscovering the Sample-Based Rarefaction Formula in the Ecological Literature." Community Ecology 2008 9:1 9(1): 121-23. https://link.springer.com/article/10.1556/ComEc.9.2008.1.14 (October 1, 2021).

Cochran, J. Kirk, Henry J. (Henry Joseph) Bokuniewicz, and Patricia L. Yager. "Encyclopedia of Ocean Sciences. Volume 1, Marine Biogeochemisty."

Cohen-Shacham, Emmanuelle et al. 2019. "Core Principles for Successfully Implementing and Upscaling Nature-Based Solutions." Environmental Science \& Policy 98: 20-29.

Convention on Biological Diversity. 2000. "COP 5 Decision V/6 Ecosystem Approach." COP 5. https://www.cbd.int/decision/cop/?id=7148 (October 13, 2021).

Cristescu, Romane H., Jonathan Rhodes, Céline Frére, and Peter B. Banks. 2013. "Is Restoring Flora the Same as Restoring Fauna? Lessons Learned from Koalas and Mining Rehabilitation." Journal of Applied Ecology 50(2): 423-31. https://onlinelibrary.wiley.com/doi/full/10.1111/1365-2664.12046 (October 13, 2021).

David, Thomas I., Jonathan Storkey, and Carly J. Stevens. 2019. "Understanding How Changing Soil Nitrogen Affects Plant-Pollinator Interactions." Arthropod-Plant Interactions $\quad 2019 \quad 13: 5 \quad 13(5): \quad 671-84$. https://link.springer.com/article/10.1007/s11829-019-09714-y (October 13, 2021).

Ebbert, Daniel. 2019. "Package 'Chisq.Posthoc.Test." https://github.com/ebbertd/chisq.posthoc.test/issues (October 3, 2021).

Ebeling, Anne et al. 2008. "How Does Plant Richness Affect Pollinator Richness and Temporal Stability of Flower Visits?" Oikos 117(12): 1808-15. https://onlinelibrary.wiley.com/doi/full/10.1111/j.1600-0706.2008.16819.x (October 13, 2021).

Fischer, Joern et al. 2021. "Making the UN Decade on Ecosystem Restoration a Social-Ecological Endeavour." Trends in Ecology \& Evolution 36(1): 20-28.

Fleishman, Erica, Reed F. Noss, and Barry R. Noon. 2006. "Utility and Limitations of Species Richness Metrics for Conservation Planning." Ecological Indicators 6(3): 543-53.

Fuentes, Laura, Beatriz Duguy, and Daniel Nadal-Sala. 2018. "Short-Term Effects of Spring Prescribed Burning on the Understory Vegetation of a Pinus Halepensis Forest in Northeastern Spain." Science of the Total Environment 610-611: 720- 
31. https://doi.org/10.1016/j.scitotenv.2017.08.050.

Gamfeldt, Lars et al. 2013. "Higher Levels of Multiple Ecosystem Services Are Found in Forests with More Tree Species." Nature Communications 2013 4:1 4(1): 1-8. https://www.nature.com/articles/ncomms2328 (October 13, 2021).

Geldmann, Jonas et al. 2018. "A Global Analysis of Management Capacity and Ecological Outcomes in Terrestrial Protected Areas." Conservation Letters 11(3): 14. https://doi.org/10.1111/conl.12434 (May 13, 2021).

GILBERT-NORTON, LYNNE, RYAN WILSON, JOHN R. STEVENS, and KAREN H. BEARD. 2010. "A Meta-Analytic Review of Corridor Effectiveness." Conservation Biology 24(3): 660-68. https://onlinelibrary.wiley.com/doi/full/10.1111/j.15231739.2010.01450.x (October 13, 2021).

Girardin, Cécile A. J. et al. 2021. "Nature-Based Solutions Can Help Cool the Planet — If We Act Now." Nature 2021 593:7858 593(7858): 191-94. https://www.nature.com/articles/d41586-021-01241-2 (September 30, 2021).

Gray, Claudia L. et al. 2016. "Local Biodiversity Is Higher inside than Outside Terrestrial Protected Areas Worldwide." Nature Communications 7(1): 1-7. www.nature.com/naturecommunications (May 13, 2021).

Hedges, L. V., J. Gurevitch, and P. S. Curtis. 1999. "The Meta-Analysis of Response Ratios in Experimental Ecology." Ecology 80(4): 1150-56. https://doi.org/10.1890/0012-9658(1999)080[1150:TMAORR]2.0.CO;2 (October 1, 2021).

Heilmayr, Robert, Cristian Echeverría, and Eric F. Lambin. 2020. "Impacts of Chilean Forest Subsidies on Forest Cover, Carbon and Biodiversity." Nature Sustainability 2020 3:9 3(9): 701-9. https://www.nature.com/articles/s41893-020-0547-0 (September 29, 2021).

Hesterberg, "Package T. 'Resample."” https://cran.rproject.org/web/packages/resample/index.html (October 1, 2021).

Humbert, Jean Yves, Jaboury Ghazoul, and Thomas Walter. 2009. "Meadow Harvesting Techniques and Their Impacts on Field Fauna." Agriculture, Ecosystems \& Environment 130(1-2): 1-8.

"IPBES-IPCC CO-SPONSORED WORKSHOP BIODIVERSITY AND CLIMATE CHANGE WORKSHOP REPORT." 2021. www.ipbes.net (September 30, 2021).

IPBES. 2021. "Ecosystem Health." IPBES Glossary. https://ipbes.net/glossary/ecosystem-health (October 1, 2021).

IPBCES. 2021. "Biodiversity | IPBES Secretariat." IPBES Glossary. https://ipbes.net/glossary/biodiversity (October 1, 2021).

IPCC. 2012. Managing the Risks of Extreme Events and Disasters to Advance Climate Change ... - Intergovernmental Panel on Climate Change. A Special Report of Working Groups I and II of the IPCC. https://books.google.co.uk/books?hl=en\&lr=\&id=nQg3SJtkOGwC\&oi=fnd\&pg=P R4\&ots=14FfqykuST\&sig=G-54K3ZSEmhvm$1 \mathrm{KmsO}$ aXddZCY\&redir_esc=y\#v=onepage\&q\&f=false (October 14,2021$)$. 
IPCC. 2018a. Annex I: Glossary. In: Global Warming of $1.5^{\circ} \mathrm{C}$. An IPCC Special Report on the Impacts of Global Warming of $1.5^{\circ} \mathrm{C}$ above Pre-Industrial Levels and Related Global Greenhouse Gas Emission Pathways, in the Context of Strengthening the Global Response to the Th.

IPCC. 2018b. Global Warming of $1.5^{\circ} \mathrm{C}$. An IPCC Special Report on the impacts of global warming of $1.5^{\circ} \mathrm{C}$ above pre-industrial levels and related global greenhouse gas emission pathways, in the context of strengthening the global response to the threat of climate change... Summary for Policymakers. In: Global Warming of $1.5^{\circ} \mathrm{C}$. An IPCC Special Report on the Impacts of Global Warming of $1.5^{\circ} \mathrm{C}$ above Pre-Industrial Levels and Related Global Greenhouse Gas Emission Pathways, in the Context of Strengthening the Global Response to the Threat of Climate Change, Sustainable Development, and Efforts to Eradicate Poverty .

Isbell, Forest et al. 2015. "Biodiversity Increases the Resistance of Ecosystem Productivity to Climate Extremes." Nature 2015 526:7574 526(7574): 574-77. https://www.nature.com/articles/nature15374 (October 13, 2021).

IUCN. 2012. "The IUCN Programme 2013-2016." https://portals.iucn.org/library/node/10320 (September 30, 2021).

IUCN. 2020. IUCN Global Standard for Nature-Based Solutions: A User-Friendly Framework for the Verification, Design and Scaling up of NbS: First Edition. https://doi.org/10.2305/IUCN.CH.2020.08.en (September 30, 2021).

IUCN. 2021. IUCN Definitions. https://www.iucn.org/sites/dev/files/iucn-glossary-ofdefinitions_en_2021.05.pdf (October 1, 2021).

Kimiti, David W., Corinna Riginos, and Jayne Belnap. 2017. "Low-Cost Grass Restoration Using Erosion Barriers in a Degraded African Rangeland." Restoration Ecology 25(3): 376-84.

Knight, Kevin Bracy, Emily S Seddon, and Theodore P Toombs. "A Framework for Evaluating Biodiversity Mitigation Metrics." https://doi.org/10.1007/s13280-01901266-y (June 9, 2021).

De Lamo, Xavier et al. 2020. Strengthening Synergies. www.naturemap.earth (May 14, 2021).

Leclère, David et al. 2020. "Bending the Curve of Terrestrial Biodiversity Needs an Integrated Strategy." Nature 585(7826): 551-56. https://doi.org/10.1038/s41586020-2705-y (May 13, 2021).

Lewis, Simon L., Charlotte E. Wheeler, Edward T. A. Mitchard, and Alexander Koch. 2019. "Restoring Natural Forests Is the Best Way to Remove Atmospheric Carbon." Nature $2021 \quad 568: 7750$ 568(7750): 25-28. https://www.nature.com/articles/d41586-019-01026-8 (September 29, 2021).

Liang, Jingjing et al. 2016. "Positive Biodiversity-Productivity Relationship Predominant in Global Forests." Science 354(6309).

López-Bao, José Vicente, Floor Fleurke, Guillaume Chapron, and Arie Trouwborst. 2018. "Legal Obligations Regarding Populations on the Verge of Extinction in Europe: Conservation, Restoration, Recolonization, Reintroduction." Biological Conservation 227: 319-25. 
Lyashevska, Olga, and Keith D Farnsworth. 2012. "How Many Dimensions of Biodiversity Do We Need?" Ecological Indicators 18: 485-92.

Marshall, Erica et al. 2021. "Quantifying the Impact of Vegetation-Based Metrics on Species Persistence When Choosing Offsets for Habitat Destruction." Conservation Biology 35(2): 567-77. https://onlinelibrary.wiley.com/doi/full/10.1111/cobi.13600 (October 13, 2021).

Marshall, Erica, Brendan A. Wintle, Darren Southwell, and Heini Kujala. 2020. "What Are We Measuring? A Review of Metrics Used to Describe Biodiversity in Offsets Exchanges." Biological Conservation 241: 108250.

Miller, Joseph T., Garry Jolley-Rogers, Brent D. Mishler, and Andrew H. Thornhill. 2018. "Phylogenetic Diversity Is a Better Measure of Biodiversity than Taxon Counting." Journal of Systematics and Evolution 56(6): 663-67. https://onlinelibrary.wiley.com/doi/full/10.1111/jse.12436 (October 1, 2021).

Mori, Akira S. et al. 2021. "Biodiversity-Productivity Relationships Are Key to NatureBased Climate Solutions." Nature Climate Change 2021 11:6 11(6): 543-50. https://www.nature.com/articles/s41558-021-01062-1 (September 30, 2021).

Moussy, Caroline et al. 2021. "A Quantitative Global Review of Species Population Monitoring." Conservation https://onlinelibrary.wiley.com/doi/full/10.1111/cobi.13721 (October 2, 2021).

Moya, Daniel, Jorge de las Heras, Francisco R. López-Serrano, and Pablo Ferrandis. 2015. "Post-Fire Seedling Recruitment and Morpho-Ecophysiological Responses to Induced Drought and Salvage Logging in Pinus Halepensis Mill. Stands." Forests 6(6): 1858-77.

Naeem, S. et al. 2016. "Biodiversity as a Multidimensional Construct: A Review, Framework and Case Study of Herbivory's Impact on Plant Biodiversity." Proceedings of the Royal Society B: Biological Sciences 283(1844). http://dx.doi.org/10.1098/rspb.2015.3005 (June 15, 2021).

Noss, Reed F. 1990. 4 Indicators for Monitoring Biodiversity: A Hierarchical Approach.

Oliver, T. H. et al. 2015. "Biodiversity and Resilience of Ecosystem Functions." Trends in ecology \& evolution 30(11): https://pubmed.ncbi.nlm.nih.gov/26437633/ (October 11, 2021).

Oliver, Tom H. et al. 2015. "Declining Resilience of Ecosystem Functions under Biodiversity Loss." Nature Communications 2015 6:1 6(1): 1-8. https://www.nature.com/articles/ncomms10122 (September 30, 2021).

Operandum. 2019. "What Are Hydrometeorological Hazards?" https://www.operandum-project.eu/news/what-are-hydrometeorological-hazards/ (October 14, 2021).

Osuri, Anand M. et al. 2020. "Greater Stability of Carbon Capture in Species-Rich Natural Forests Compared to Species-Poor Plantations." Environmental Research Letters 15(3): 034011. https://doi.org/10.1088/1748-9326/ab5f75 (May 14, 2021).

Paolucci, Esteban M., Hugh J. Maclsaac, and Anthony Ricciardi. 2013. "Origin Matters: Alien Consumers Inflict Greater Damage on Prey Populations than Do 
Native Consumers." Diversity and Distributions 19(8): 988-95. https://onlinelibrary.wiley.com/doi/full/10.1111/ddi.12073 (October 13, 2021).

Paudyal, Kiran et al. 2019. "Spatial Assessment of the Impact of Land Use and Land Cover Change on Supply of Ecosystem Services in Phewa Watershed, Nepal." $\begin{array}{lll}\text { Ecosystem Services } & \text { 36(March } 2018 \text { ): }\end{array}$ https://doi.org/10.1016/j.ecoser.2019.100895.

Poore, J., and T. Nemecek. 2018. "Reducing Food's Environmental Impacts through Producers and Consumers." Science 360(6392): 987-92. http://science.sciencemag.org/content/360/6392/987 (January 10, 2019).

Prendergast, J. R. et al. 1993. "Rare Species, the Coincidence of Diversity Hotspots and Conservation Strategies." Nature 1993 365:6444 365(6444): 335-37. https://www.nature.com/articles/365335a0 (October 3, 2021).

Prowse, Thomas A.A. et al. 2017. "Prescribed Burning Impacts Avian Diversity and Disadvantages Woodland-Specialist Birds Unless Long-Unburnt Habitat is Retained." Biological Conservation 215: 268-76.

Qiu, Jiangxiao, and Bradley J. Cardinale. 2020. "Scaling up Biodiversity-Ecosystem Function Relationships across Space and over Time." Ecology 101(11). https://onlinelibrary.wiley.com/doi/10.1002/ecy.3166 (January 16, 2021).

Roe, D. et al. 2021. "Investing in Nature for Development: Do Nature-Based Interventions Deliver Local Development Outcomes?" http://repo.floodalliance.net/jspui/handle/44111/4166 (September 30, 2021).

Ruaro, Renata, Éder André Gubiani, Sidinei Magela Thomaz, and Roger Paulo Mormul. 2020. "Nonnative Invasive Species Are Overlooked in Biological Integrity Assessments." Biological Invasions $2020 \quad 23: 1 \quad 23(1)$ : 83-94. https://link.springer.com/article/10.1007/s10530-020-02357-8 (October 13, 2021).

Sala, Enric, and Sylvaine Giakoumi. 2018. "No-Take Marine Reserves Are the Most Effective Protected Areas in the Ocean." ICES Journal of Marine Science 75(3): 1166-68. https://academic.oup.com/icesjms/article/75/3/1166/4098821 (May 13, 2021).

Scheidel, Arnim, and Courtney Work. 2018. "Forest Plantations and Climate Change Discourses: New Powers of 'Green' Grabbing in Cambodia." Land Use Policy 77: 9-18.

Schwarz, Nina et al. 2017. "Understanding Biodiversity-Ecosystem Service Relationships in Urban Areas: A Comprehensive Literature Review." Ecosystem Services 27: 161-71.

Scyphers, Steven B., Sean P. Powers, Kenneth L. Heck, and Dorothy Byron. 2011. "Oyster Reefs as Natural Breakwaters Mitigate Shoreline Loss and Facilitate Fisheries." PLOS ONE 6(8).

Seddon, Nathalie, Elizabeth Daniels, et al. 2020. "Global Recognition of the Importance of Nature-Based Solutions to the Impacts of Climate Change." Global Sustainability $\quad 3 . \quad$ https://www.cambridge.org/core/journals/globalsustainability/article/global-recognition-of-the-importance-of-naturebased- 
solutions-to-the-impacts-of-climate-

change/31E756CC7792FB9DF717E3DAEE1381AC (October 15, 2021).

Seddon, Nathalie, Alexandre Chausson, et al. 2020. "Understanding the Value and Limits of Nature-Based Solutions to Climate Change and Other Global Challenges." Philosophical Transactions of the Royal Society B: Biological Sciences 375(1794).

Seddon, Nathalie et al. 2021. "Getting the Message Right on Nature-Based Solutions to Climate Change." Global Change Biology 27(8): 1518-46. https://onlinelibrary.wiley.com/doi/full/10.1111/gcb.15513 (September 30, 2021).

Sekercioglu, Cagan H. 2010. "Ecosystem Functions and Services." In Conservation Biology for All, 45-72. https://books.google.co.uk/books?hl=en\&lr=\&id=MxIUDAAAQBAJ\&oi=fnd\&pg=P A45\&dq=ecosystem+functions+support+services+\&ots=GoOEAYHiPt\&sig=R83 $q H Z J c l-c P y t h p V h q g 5 R F P N U s \# v=0$ nepage $\& q=e c o s y s t e m$ functions support services\&f $f=$ false (October 13, 2021).

Silliman, Brian R. et al. 2015. "Facilitation Shifts Paradigms and Can Amplify Coastal Restoration Efforts." Proceedings of the National Academy of Sciences of the United States of America 112(46): 14295-300.

Smith, A. C. et al. 2017. "How Natural Capital Delivers Ecosystem Services: A Typology Derived from a Systematic Review." Ecosystem Services 26: 111-26.

Smith, Alison, and Alexandre Chausson. 2021. Nature-Based Solutions in UK Climate Adaptation Policy. A Report Prepared by the Nature-Based Solutions Initiative at the University of Oxford for WWF-UK and RSPB. https://www.rspb.org.uk/globalassets/downloads/policy-briefings/nature-basedsolutions-adaption-report.pdf (October 15, 2021).

Society for Ecological Restoration International Science \& Policy Working Group. 2004. "The SER International Primer on Ecological Restoration." www.ser.org \& Tucson: Society for Ecological Restoration International. . www.ser.org (September 30, 2021).

Spake, Rebecca, and C. Patrick Doncaster. 2017. "Use of Meta-Analysis in Forest Biodiversity Research: Key Challenges and Considerations." Forest Ecology and Management 400: 429-37.

Strassburg, Bernardo B. N. et al. 2020. "Global Priority Areas for Ecosystem Restoration." Nature $2020 \quad 586: 7831 \quad$ 586(7831): $724-29$. https://www.nature.com/articles/s41586-020-2784-9 (September 30, 2021).

Uebel, Konrad, Kerrie A. Wilson, and Luke P. Shoo. 2017. "Assisted Natural Regeneration Accelerates Recovery of Highly Disturbed Rainforest." Ecological Management \& Restoration 18(3): 231-38. https://onlinelibrary.wiley.com/doi/full/10.1111/emr.12277 (September 30, 2021).

UNEP-Nairobi Convention/WIOMSA. 2020. Guidelines on Seagrass Ecosystem Restoration for the Western Indian Ocean Region / UNEP - UN Environment Programme. https://www.unep.org/resources/report/guidelines-seagrassecosystem-restoration (October 2, 2021). 
USEPA. 2016. A Practitioner's Guide to the Biological Condition Gradient: A Framework to Describe Incremental Change in Aquatic Ecosystems. Washington, DC. https://www.epa.gov/sites/default/files/2016-02/documents/bcg-practionersguide-report.pdf (October 13, 2021).

Wang, Chang Ting et al. 2013. "Effects of Establishing an Artificial Grassland on Vegetation Characteristics and Soil Quality in a Degraded Meadow." Israel Journal ofEcology \& Evolution 59(3): 141-53.

Welden, E. A., Alexandre Chausson, and Marina S. Melanidis. 2021. "Leveraging Nature-Based Solutions for Transformation: Reconnecting People and Nature." People and Nature 00: 1-12. https://onlinelibrary.wiley.com/doi/full/10.1002/pan3.10212 (September 30, 2021).

Williams, Jack E. et al. 2015. "Climate Change Adaptation and Restoration of Western Trout Streams: Opportunities and Strategies." Fisheries 40(7): 304-17.

Yu, Guo an et al. 2012. "Rehabilitation of a Debris-Flow Prone Mountain Stream in Southwestern China - Strategies, Effects and Implications." Journal of Hydrology 414-415: 231-43. http://dx.doi.org/10.1016/j.jhydrol.2011.10.036. 


\section{TABLES}

\section{Table 1: Definitions of key social-ecological terms}

\begin{tabular}{|l|}
\hline Term \\
\hline Biodiversity \\
\hline $\begin{array}{l}\text { Climate change } \\
\text { adaptation outcome }\end{array}$ \\
\hline
\end{tabular}

Definition

'The variability among living organisms from all sources including terrestrial, marine and other aquatic ecosystems and the ecological complexes of which they are a part. This includes variation in genetic, phenotypic, phylogenetic, and functional attributes, as well as changes in abundance and distribution over time and space within and among species, biological communities and ecosystems' (IPBES, 2021).

An outcome of an intervention which reduces at least one impact of climate change on people. Here we refer to 'climate change adaptation outcomes' as equivalent to the 'climate impact outcomes' in Chausson, Turner et al. (2020), which address both impacts that have been explicitly linked to climate change (climate impacts are "the effects on natural and human systems of physical events, of disasters, and of climate change" (IPCC 2012)) and hydrometeorological hazards which may be affected by climate change (a "process or phenomenon of atmospheric, hydrological or oceanographic nature that may cause loss of life, injury or other health impacts, property damage, loss of livelihoods and services, social and economic disruption, or environmental damage" (Operandum 2019)).

Climate change
mitigation outcome
Ecological resilience

An outcome of an intervention which reduces emission or enhances sinks of greenhouse gases (IPCC 2018a).

'The ability of a system to absorb or recover from disturbance and change, while maintaining its functions and services' (IUCN 2021). Such absorption of disturbance is ecological resistance: 'The ability of an ecosystem to withstand disturbance without undergoing a phase shift or losing neither structure nor function' (IUCN 2021).

Ecosystem health 'The state or condition of an ecosystem in which its dynamic attributes are expressed within the normal ranges of activity relative to its ecological state of development' (SER, 2004)). This comprises both biotic and abiotic features of ecosystems, including biodiversity.

'Ecosystem health is a metaphor used to describe the condition of an ecosystem, by analogy with human health. Note that there is no universally accepted benchmark for a healthy ecosystem. Rather, the apparent health status of an ecosystem can vary, depending upon which metrics are employed in judging it, and which societal aspirations are driving the assessment' (IPBES, 2021).

'The health paradigm is based on multiple state comparisons of ecosystem resiliency and stability and is an evolving concept. To be healthy and sustainable an ecosystem should maintain its metabolic activity level and its internal structure and organization and resist external stresses' (Cochran, Bokuniewicz, \& Yager, 2019)

Note that ecosystem health is a distinct term from ecosystem integrity and intactness (SER, 2004).

Nature-based

intervention

Actions involving management, restoration or protection of biodiversity, ecosystems, or ecosystem services, or involving ecosystem creation and subsequent management (Chausson et al. 2020). Some may qualify as nature-based solutions (see definition above) but it was beyond the scope of this review to identify which interventions would qualify.

Nature-based solution 'Actions to protect, sustainably manage and restore natural or modified ecosystems that address societal challenges effectively and adaptively, simultaneously providing human wellbeing and biodiversity' benefits (Cohen-Shacham et al. 2019; IUCN 2012).

Nature-based solutions should also meet the IUCN Global Standard (IUCN 2020), including being led by local communities who should be the primary beneficiaries of a project. 
Table 2: Ecosystem health broad metric categories, metric types and definitions used to code the ecosystem health outcomes of interventions.

\begin{tabular}{|c|c|c|}
\hline Broad category & Metric type & Definition \\
\hline \multirow[t]{9}{*}{ Diversity } & Genetic diversity & $\begin{array}{l}\text { Measures of the number or diversity of genetic } \\
\text { polymorphisms or genotypes (Avolio et al. 2012). }\end{array}$ \\
\hline & $\begin{array}{l}\text { Phylogenetic } \\
\text { diversity }\end{array}$ & $\begin{array}{l}\text { Measures of branch lengths on a phylogenetic tree for } \\
\text { a given group of species (Miller et al. 2018). }\end{array}$ \\
\hline & Species richness & $\begin{array}{l}\text { The number of species represented in an ecological } \\
\text { community, landscape or region, a.k.a. alpha } \\
\text { diversity. Usually measured by using species density } \\
\text { (number of species found per sampled area) as a } \\
\text { proxy. }\end{array}$ \\
\hline & Species evenness & $\begin{array}{l}\text { The relative abundance of different species in a } \\
\text { community, landscape or region, a.k.a. beta diversity. }\end{array}$ \\
\hline & Species diversity & $\begin{array}{l}\text { Metrics combining the number of species present in } \\
\text { an ecosystem and relative abundance of each of } \\
\text { those species, e.g. Shannon-Wiener diversity index. }\end{array}$ \\
\hline & Generic richness & $\begin{array}{l}\text { The number of genera present in a community, } \\
\text { landscape or region. }\end{array}$ \\
\hline & $\begin{array}{l}\text { Family and above } \\
\text { richness }\end{array}$ & $\begin{array}{l}\text { The number of different families (or higher taxonomic } \\
\text { group) present in a community, landscape or region. }\end{array}$ \\
\hline & Functional diversity & $\begin{array}{l}\text { The diversity of functional traits within a population, } \\
\text { community, landscape or region; includes measures } \\
\text { of functional redundancy. }{ }^{1}\end{array}$ \\
\hline & Habitat diversity & $\begin{array}{l}\text { Metrics of the diversity of habitats within a landscape, } \\
\text { e.g. applying the Shannon-Wiener diversity index to } \\
\text { habitats. }{ }^{2}\end{array}$ \\
\hline \multirow[t]{6}{*}{ Biomass } & Biomass & $\begin{array}{l}\text { Quantities per unit area of living or dead biomass of } \\
\text { plants, animals or microbes. }\end{array}$ \\
\hline & Canopy cover & $\begin{array}{l}\text { Absolute or proportional canopy cover, and vertical } \\
\text { canopy structure. }\end{array}$ \\
\hline & Habitat extent & $\begin{array}{l}\text { Area covered by habitat, including vegetation, coral } \\
\text { and waterbodies, unless measured as canopy cover } \\
\text { or litter cover. }\end{array}$ \\
\hline & Habitat density & $\begin{array}{l}\text { Proportional cover by a habitat, including vegetation, } \\
\text { coral and waterbodies, unless measured as canopy } \\
\text { cover or litter cover. }\end{array}$ \\
\hline & Litter cover & Absolute or proportional cover of leaf litter or dung. \\
\hline & Stem density & $\begin{array}{l}\text { The absolute or proportional number of stems or } \\
\text { individual plants. }\end{array}$ \\
\hline \multirow{6}{*}{$\begin{array}{l}\text { Ecosystem } \\
\text { functioning and } \\
\text { population dynamics }\end{array}$} & Age structure & $\begin{array}{l}\text { Change in the age structure of populations, such as } \\
\text { age of animals or diameter of trees. }\end{array}$ \\
\hline & $\begin{array}{l}\text { Ecological } \\
\text { vulnerability }\end{array}$ & $\begin{array}{l}\text { Assessing ecological vulnerability by assessing its } \\
\text { sub-components: exposure, sensitivity and adaptive } \\
\text { capacity. }\end{array}$ \\
\hline & Elevation rate & $\begin{array}{l}\text { Vertical changes in sediment, reefs or marshes } \\
\text { through accretion or growth. }\end{array}$ \\
\hline & Functional identity & $\begin{array}{l}\text { Metrics indicating dominant functional features within } \\
\text { communities or species groups, e.g. mean trait } \\
\text { values, and relative abundance of competitive, } \\
\text { stress-tolerant and ruderal strategists (Schwarz et al. } \\
\text { 2017). }\end{array}$ \\
\hline & Growth rate & $\begin{array}{l}\text { Growth rate of individuals, e.g. change in tree height } \\
\text { over time. }\end{array}$ \\
\hline & Phenology & $\begin{array}{l}\text { Changes in phenology or presence of phenological } \\
\text { mismatch among taxa or between taxa and seasonal } \\
\text { events. }\end{array}$ \\
\hline
\end{tabular}




\begin{tabular}{|c|c|c|}
\hline & Reproductive rate & $\begin{array}{l}\text { Reproductive rate of species e.g. fledglings per adult } \\
\text { male, young-of-the year fish numbers, or related } \\
\text { measures e.g. runner length. }\end{array}$ \\
\hline & Recovery rate & $\begin{array}{l}\text { Measures of the recovery rate (sometimes referred to } \\
\text { as 'resilience') after disturbances such as extreme } \\
\text { climatic events. This is restricted to empirical } \\
\text { measures of resilience, rather than use of proxies } \\
\text { such as functional redundancy. }\end{array}$ \\
\hline & Resistance & $\begin{array}{l}\text { Measures of ecosystem or species ability to withstand } \\
\text { disturbances such as extreme climatic events. This is } \\
\text { restricted to empirical measures of resistance, rather } \\
\text { than use of proxies such as functional redundancy. }\end{array}$ \\
\hline & Survival rate & $\begin{array}{l}\text { The survival rate within a population, e.g. of trees } \\
\text { after planting. }\end{array}$ \\
\hline $\begin{array}{l}\text { Ecosystem } \\
\text { composition }\end{array}$ & $\begin{array}{l}\text { Community } \\
\text { composition }\end{array}$ & $\begin{array}{l}\text { Identity and relative abundance of (all) different taxa } \\
\text { in a community, which could be grouped by } \\
\text { phylogeny, niche or function. E.g. the proportion of } \\
\text { native and non-native species, the community-level } \\
\text { physiological profiles of soil and microbial } \\
\text { communities, and analyses of species composition } \\
\text { similarities between communities. }\end{array}$ \\
\hline & Organism density & $\begin{array}{l}\text { Abundance of taxa not defined at the species level, } \\
\text { e.g. number of benthic organisms per unit area. }\end{array}$ \\
\hline & $\begin{array}{l}\text { Species } \\
\text { abundance }\end{array}$ & $\begin{array}{l}\text { The number of individuals of a given species in a } \\
\text { community, landscape or region. }\end{array}$ \\
\hline & Taxa presence & $\begin{array}{l}\text { The presence (not abundance) of a given taxon, e.g. } \\
\text { using thresholds to determine whether a given taxon } \\
\text { can survive, or reported presence of a keystone, } \\
\text { endangered or invasive species. }\end{array}$ \\
\hline Habitat quality & Habitat quality & $\begin{array}{l}\text { Metrics of the quality of habitat that do not fit into other } \\
\text { metric categories, such as the quality of habitat for } \\
\text { supporting specific taxa, the presence of particular } \\
\text { landscape features, soil quality, or habitat } \\
\text { conservation status. }\end{array}$ \\
\hline Landscape structure & $\begin{array}{l}\text { Connectivity and } \\
\text { fragmentation }\end{array}$ & $\begin{array}{l}\text { Fragmentation is transformation of larger expanses of } \\
\text { habitat into a number of patches with a smaller total } \\
\text { area, isolated from each other by a matrix of habitats } \\
\text { unlike the original. Connectivity is the degree to which } \\
\text { separate patches of habitat are connected, allowing } \\
\text { organisms to move between patches. }\end{array}$ \\
\hline Conservation status & $\begin{array}{l}\text { Conservation } \\
\text { status }\end{array}$ & $\begin{array}{l}\text { Change in conservation status or likelihood of } \\
\text { extinction, for a taxon. }\end{array}$ \\
\hline Unspecified & $\begin{array}{l}\text { Perceived overall } \\
\text { change }\end{array}$ & $\begin{array}{l}\text { Statements of changes in ecosystem health where it } \\
\text { is not made explicit which aspect of ecosystem health } \\
\text { or biodiversity was affected. }\end{array}$ \\
\hline
\end{tabular}


Table 3: Examples of ecosystem health outcomes of interventions which were selected to cover a range of habitat and intervention types, each with ecosystem health outcomes across multiple broad metric categories, with either native or unclear species identity.

\begin{tabular}{|c|c|c|c|c|c|c|c|}
\hline Study & Intervention & $\begin{array}{l}\text { Data quality } \\
\text { notes }\end{array}$ & $\begin{array}{l}\text { Broad metric } \\
\text { category }\end{array}$ & Metric type & Outcome & Outcome description & $\begin{array}{l}\text { Species } \\
\text { identity }\end{array}$ \\
\hline \multirow[t]{5}{*}{$\begin{array}{l}\text { Williams } \\
\text { et al. } 2015\end{array}$} & \multirow{5}{*}{$\begin{array}{l}\text { Watershed } \\
\text { restoration } \\
\text { including limiting } \\
\text { grazing in the hot } \\
\text { season, planting } \\
\text { and fencing in the } \\
\text { riparian zone, and } \\
\text { reconnection of } \\
\text { three tributaries to } \\
\text { the main river by } \\
\text { replacing culverts } \\
\text { and adding fish- } \\
\text { friendly structures } \\
\text { to irrigation } \\
\text { diversions. Nevada, } \\
\text { USA }\end{array}$} & \multirow{5}{*}{$\begin{array}{l}\text { Methodology: } \\
\text { low detail } \\
\text { Counterfactual: } \\
\text { baseline } \\
\text { Authors } \\
\text { associated with } \\
\text { intervention }\end{array}$} & Habitat quality & $\begin{array}{l}\text { Habitat } \\
\text { quality }\end{array}$ & Positive & $\begin{array}{l}\text { Aerial photography showed replacement } \\
\text { of upland vegetation with riparian } \\
\text { vegetation, which the authors framed as } \\
\text { 'habitat improvements'. The authors also } \\
\text { noted that recolonization by beavers led } \\
\text { to an increase in the quality of habitat for } \\
\text { fish, waterfowl and other animals. }\end{array}$ & Unclear \\
\hline & & & $\begin{array}{l}\text { Ecosystem } \\
\text { composition }\end{array}$ & $\begin{array}{l}\text { Species } \\
\text { abundance }\end{array}$ & Positive & $\begin{array}{l}\text { Beaver and fish populations increased } \\
\text { following the intervention, with an } 8.6 \text {-fold } \\
\text { increase in the number of fish caught in } \\
\text { surveys. }\end{array}$ & Unclear \\
\hline & & & $\begin{array}{l}\text { Ecosystem } \\
\text { composition }\end{array}$ & $\begin{array}{l}\text { Taxa } \\
\text { presence }\end{array}$ & Positive & $\begin{array}{l}\text { Presence of beavers - an ecosystem } \\
\text { engineer, as well as fish, waterfowl, other } \\
\text { birds, muskrats, mule deer, mink and } \\
\text { raccoons. }\end{array}$ & Unclear \\
\hline & & & $\begin{array}{l}\text { Ecosystem } \\
\text { functioning and } \\
\text { population } \\
\text { dynamics }\end{array}$ & $\begin{array}{l}\text { Reproductive } \\
\text { rate }\end{array}$ & Positive & $\begin{array}{l}\text { Evidence for an increase in successful } \\
\text { fish (Yellowstone Cutthroat Trout) } \\
\text { spawning, as indicated by the number of } \\
\text { young-of-the-year fish. }\end{array}$ & Native \\
\hline & & & $\begin{array}{l}\text { Ecosystem } \\
\text { functioning and } \\
\text { population } \\
\text { dynamics }\end{array}$ & Age structure & Positive & $\begin{array}{l}\text { Increased incidence of migratory-sized } \\
\text { fish (Yellowstone Cutthroat Trout) after } \\
\text { the intervention, with this holding true in } \\
\text { one of the worst drought years on record. } \\
\text { The authors suggest that migratory fish } \\
\text { are now able to escape areas of habitat } \\
\text { disturbance or degradation by entering } \\
\text { other streams, and hence that the system } \\
\text { as a whole is functioning more like it did } \\
\text { historically. }\end{array}$ & Native \\
\hline $\begin{array}{l}\text { Silliman et } \\
\text { al. } 2015\end{array}$ & $\begin{array}{lr}\text { Salt } & \text { marsh } \\
\text { restoration } & \\
\text { comparing } & \text { two } \\
\text { contrasting } & \end{array}$ & $\begin{array}{l}\text { Methodology: } \\
\text { high detail }\end{array}$ & $\begin{array}{l}\text { Ecosystem } \\
\text { functioning and } \\
\text { population } \\
\text { dynamics }\end{array}$ & Survival rate & Positive & $\begin{array}{l}\text { Average survivorship of transplanted } \\
\text { plugs of marsh grass was } 56-84 \% \text { for } \\
\text { dispersed treatments and } 100 \% \text { in } \\
\text { clumped treatments. }\end{array}$ & Native \\
\hline
\end{tabular}




\begin{tabular}{|c|c|c|c|c|c|c|c|}
\hline & \multirow{3}{*}{ 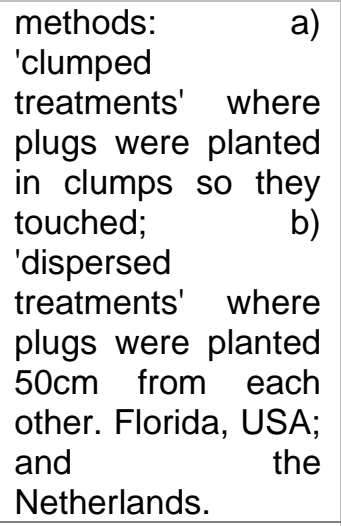 } & \multirow{3}{*}{$\begin{array}{l}\text { Counterfactual: } \\
\text { baseline } \\
\text { Field experiment } \\
\text { implemented by } \\
\text { authors }\end{array}$} & Biomass & Biomass & Positive & $\begin{array}{l}\text { Aboveground biomass was almost } 200 \% \\
\text { higher when transplanted plugs were } \\
\text { clumped rather than dispersed. }\end{array}$ & Native \\
\hline & & & Biomass & Stem density & Positive & $\begin{array}{l}\text { Stem density was } 80 \% \text { higher when } \\
\text { transplanted plugs were clumped rather } \\
\text { than dispersed }\end{array}$ & Native \\
\hline & & & $\begin{array}{l}\text { Ecosystem } \\
\text { functioning and } \\
\text { population } \\
\text { dynamics }\end{array}$ & $\begin{array}{l}\text { Reproductive } \\
\text { rate }\end{array}$ & Positive & $\begin{array}{l}\text { Maximal runner length was } 143 \% \text { higher } \\
\text { when transplanted plugs were clumped } \\
\text { rather than dispersed. Runner length } \\
\text { reflects dispersal potential. }\end{array}$ & Native \\
\hline \multirow[t]{4}{*}{$\begin{array}{l}\text { Scyphers } \\
\text { et al. } 2011\end{array}$} & \multirow{4}{*}{$\begin{array}{l}\text { Creation of subtidal } \\
\text { breakwater oyster } \\
\text { reefs: loose oyster } \\
\text { shell was placed on } \\
\text { fabric and secured } \\
\text { with a plastic mesh, } \\
\text { designed to act as a } \\
\text { substrate for oyster } \\
\text { larvae. Alabama, } \\
\text { USA }\end{array}$} & \multirow{4}{*}{$\begin{array}{l}\text { Methodology: } \\
\text { high detail } \\
\text { Counterfactual: } \\
\text { baseline (for } \\
\text { juvenile oyster } \\
\text { density); none } \\
\text { (for oyster } \\
\text { survival rate); } \\
\text { space for time } \\
\text { substitution (for } \\
\text { all other metrics) } \\
\text { Field experiment } \\
\text { implemented by } \\
\text { authors }\end{array}$} & $\begin{array}{l}\text { Ecosystem } \\
\text { composition }\end{array}$ & $\begin{array}{l}\text { Species } \\
\text { abundance }\end{array}$ & Positive & $\begin{array}{l}\text { The density (individuals per unit area) of } \\
\text { juvenile oysters increased after the } \\
\text { initiation of the intervention, and then } \\
\text { decreased, being replaced by adult } \\
\text { oysters which increased in density over } \\
\text { time, or increased and the plateaued. }\end{array}$ & Native \\
\hline & & & $\begin{array}{l}\text { Ecosystem } \\
\text { functioning and } \\
\text { population } \\
\text { dynamics }\end{array}$ & Survival rate & Unclear & $\begin{array}{l}\text { The mortality rate of oysters peaked } \\
\text { between a year and } 17 \text { months after } \\
\text { restoration, depending on the site, and } \\
\text { was stated to be 'high' by the authors, } \\
\text { who attributed to either predation or } \\
\text { physical disturbance. The outcome } \\
\text { direction is unclear because there was no } \\
\text { counterfactual for this metric. }\end{array}$ & Native \\
\hline & & & Diversity & $\begin{array}{l}\text { Species } \\
\text { richness }\end{array}$ & Positive & $\begin{array}{l}\text { Species richness was significantly higher } \\
\text { near reefs than controls for species } \\
\text { captured with } 10 \mathrm{~cm} \text { gillnets, with no } \\
\text { significant different using } 5 \mathrm{~cm} \text { gillnets. }\end{array}$ & Unclear \\
\hline & & & $\begin{array}{l}\text { Ecosystem } \\
\text { composition }\end{array}$ & $\begin{array}{l}\text { Community } \\
\text { composition }\end{array}$ & Unclear & $\begin{array}{l}\text { There were some differences in } \\
\text { community composition between the reef } \\
\text { and control sites (for fish captured with } \\
10 \mathrm{~cm} \text { gillnets, and smaller and juvenile } \\
\text { fish, and invertebrates captured with } \\
\text { seines), but the authors did not clarify }\end{array}$ & Unclear \\
\hline
\end{tabular}




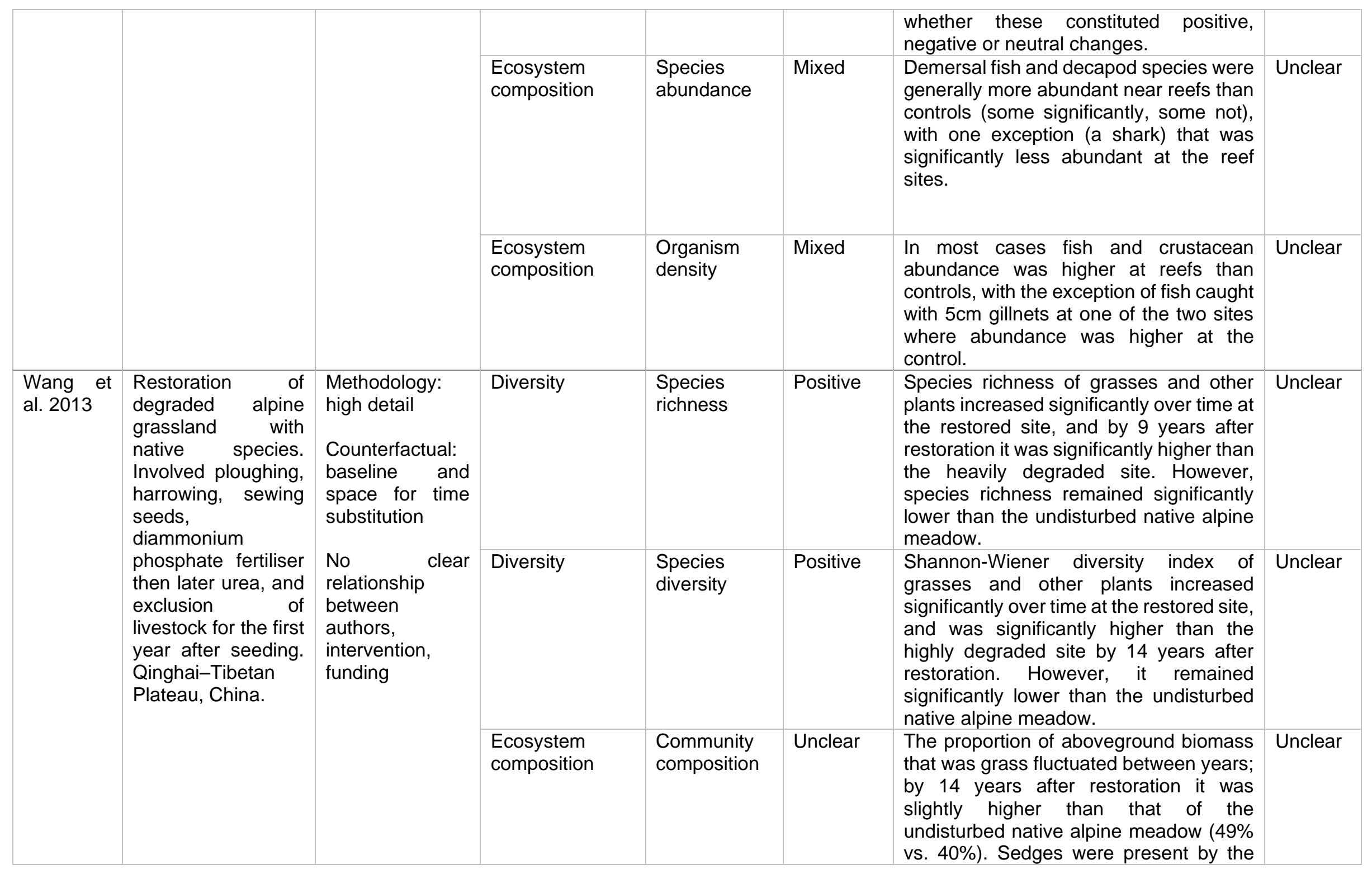




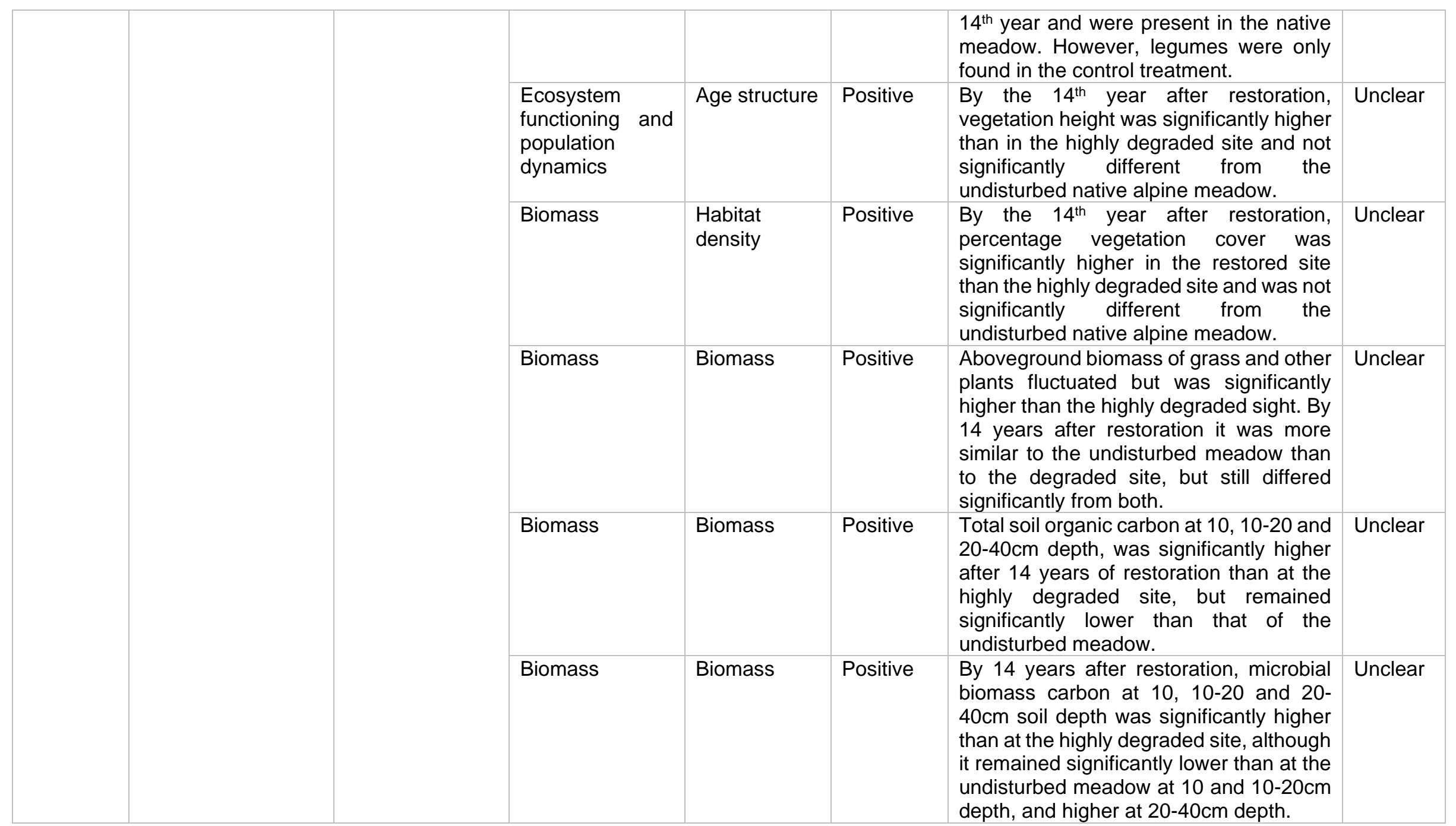


Table 4: Examples of negative outcomes from interventions, and the context in which these negative outcomes were found including other outcomes from the intervention, and authors' comments on the reason for negative outcomes.

\begin{tabular}{|c|c|c|c|c|c|c|c|c|}
\hline Study & Intervention & $\begin{array}{l}\text { Data quality } \\
\text { notes }\end{array}$ & $\begin{array}{l}\text { Broad } \\
\text { metric } \\
\text { category }\end{array}$ & Metric type & $\begin{array}{l}\text { Outcome } \\
\text { direction }\end{array}$ & $\begin{array}{l}\text { Outcome } \\
\text { description }\end{array}$ & $\begin{array}{l}\text { Species } \\
\text { identity }\end{array}$ & Context \\
\hline $\begin{array}{l}\text { Paudyal } \\
\text { et al. } \\
2019\end{array}$ & $\begin{array}{l}\text { Community-based } \\
\text { forestry involving } \\
\text { restoring degraded } \\
\text { forest through } \\
\text { planting trees on } \\
\text { barren land and } \\
\text { protecting } \\
\text { degraded forests; } \\
\text { local people were } \\
\text { also granted } \\
\text { formal rights to use } \\
\text { forest products. } \\
\text { Phewa watershed, } \\
\text { Nepal. }\end{array}$ & $\begin{array}{l}\text { Methodology: } \\
\text { high detail } \\
\text { Counterfactual: } \\
\text { baseline } \\
\text { No clear } \\
\text { relationship } \\
\text { between } \\
\text { authors, } \\
\text { intervention, } \\
\text { funding }\end{array}$ & $\begin{array}{l}\text { Community } \\
\text { composition }\end{array}$ & $\begin{array}{l}\text { Taxa } \\
\text { presence }\end{array}$ & Negative & $\begin{array}{l}\text { A workshop } \\
\text { with local } \\
\text { stakeholders } \\
\text { found that the } \\
\text { number of } \\
\text { species of } \\
\text { invasive plant } \\
\text { was } \\
\text { perceived to } \\
\text { have } \\
\text { increased as } \\
\text { a result of the } \\
\text { intervention. }\end{array}$ & $\begin{array}{l}\text { Non- } \\
\text { native }\end{array}$ & $\begin{array}{l}\text { The intervention also had positive } \\
\text { outcomes for aboveground } \\
\text { biomass, habitat extent, and } \\
\text { habitat connectivity and } \\
\text { intactness; it had a mixed outcome } \\
\text { for habitat provision (improvement } \\
\text { across four indicators, and } \\
\text { deterioration across three } \\
\text { indicators). A steep increase in } \\
\text { pollutant materials was also } \\
\text { reported, although this was not } \\
\text { coded as an ecosystem health } \\
\text { outcome. }\end{array}$ \\
\hline $\begin{array}{l}\text { Cao, } \\
\text { Chen, } \\
\text { and Yu } \\
2009\end{array}$ & $\begin{array}{l}\text { Afforestation with } \\
\text { five different non- } \\
\text { native tree } \\
\text { species, some in } \\
\text { single species } \\
\text { plantations, some } \\
\text { with two species } \\
\text { combined. } \\
\text { Shaanxi Province, } \\
\text { China. }\end{array}$ & $\begin{array}{l}\text { Methodology: } \\
\text { high detail } \\
\text { Counterfactual: } \\
\text { baseline } \\
\text { No clear } \\
\text { relationship } \\
\text { between } \\
\text { authors, } \\
\text { intervention, } \\
\text { funding }\end{array}$ & Biomass & $\begin{array}{l}\text { Habitat } \\
\text { extent }\end{array}$ & Negative & $\begin{array}{l}\text { Afforestation } \\
\text { led to a net } \\
\text { decrease in } \\
\text { total } \\
\text { vegetation } \\
\text { cover over } \\
\text { time, and } \\
\text { vegetation in } \\
\text { cover in } \\
\text { afforested } \\
\text { areas was } \\
32 \% \text { lower in } \\
\text { afforested } \\
\text { plots after } \\
\text { seven years } \\
\text { than plots } \\
\text { with natural }\end{array}$ & Mixed & $\begin{array}{l}\text { Although the afforested plots led to } \\
\text { a decrease in native vegetation } \\
\text { cover, there was an increase in } \\
\text { lichen percentage cover and } \\
\text { species richness (mixture of native } \\
\text { and non-native) over time. } \\
\text { However, overall vegetation cover, } \\
\text { lichen percentage cover and } \\
\text { species richness all increased to a } \\
\text { lesser extent than plots with } \\
\text { natural regeneration. The authors } \\
\text { also reported survival rates and } \\
\text { how species canopy cover varied } \\
\text { between plots, but the effects of } \\
\text { the intervention of these metrics } \\
\text { were unclear. }\end{array}$ \\
\hline
\end{tabular}




\begin{tabular}{|c|c|c|c|c|c|c|c|c|}
\hline & & & & & & $\begin{array}{l}\text { regeneration } \\
\text { (where } \\
\text { farming was } \\
\text { abandoned). } \\
\text { Native } \\
\text { vegetation } \\
\text { cover } \\
\text { decreased by } \\
31 \% \text { after } \\
\text { seven years } \\
\text { of the } \\
\text { intervention, } \\
\text { due to being } \\
\text { destroyed to } \\
\text { make way for } \\
\text { tree planting } \\
\text { and dig } \\
\text { trenches to } \\
\text { channel to } \\
\text { water to } \\
\text { trees. }\end{array}$ & & \\
\hline & & & $\begin{array}{l}\text { Ecosystem } \\
\text { composition }\end{array}$ & $\begin{array}{l}\text { Community } \\
\text { compo- } \\
\text { sition }\end{array}$ & Negative & $\begin{array}{l}\text { The } \\
\text { intervention } \\
\text { led to the } \\
\text { replacement } \\
\text { of native } \\
\text { vegetation by } \\
\text { a tree- } \\
\text { dominated } \\
\text { community, } \\
\text { with fewer } \\
\text { species } \\
\text { overall, and } \\
\text { more exotic } \\
\text { tree species. }\end{array}$ & Mixed & \\
\hline $\begin{array}{l}\text { Moya et } \\
\text { al. } 2015\end{array}$ & $\begin{array}{l}\text { Salvage logging } \\
\text { (removal of dead } \\
\text { standing trees) six } \\
\text { months after a fire }\end{array}$ & $\begin{array}{l}\text { Methodology: } \\
\text { high detail }\end{array}$ & $\begin{array}{l}\text { Ecosystem } \\
\text { functioning } \\
\text { and }\end{array}$ & $\begin{array}{l}\text { Survival } \\
\text { rate }\end{array}$ & Negative & $\begin{array}{l}\text { Pine seedling } \\
\text { survival was } \\
\text { zero in areas } \\
\text { with salvage }\end{array}$ & Native & $\begin{array}{l}\text { The authors attribute the poor } \\
\text { seedling survival to increased } \\
\text { water stress and reduced nutrient } \\
\text { availability caused by removing }\end{array}$ \\
\hline
\end{tabular}




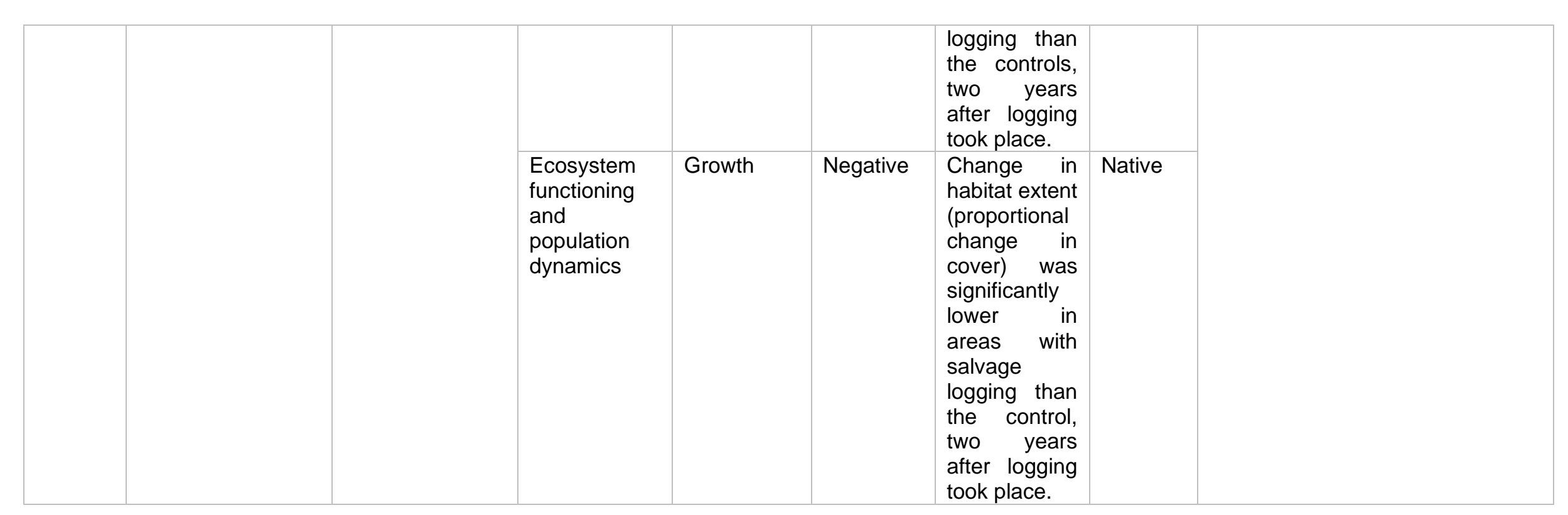


Table 5: Climate change adaptation outcomes of interventions with positive ecosystem health outcomes, subdivided by broad ecosystem health metric category.

\begin{tabular}{|l|l|l|l|l|l|}
\hline \multirow{2}{*}{ Broad ecosystem health metric category } & \multicolumn{5}{l}{ Climate change adaptation outcome direction } \\
\cline { 2 - 6 } & Positive & Negative & Mixed & No effect & Unclear \\
\hline Diversity & 1 & 0 & 0 & 0 & 0 \\
\hline Biomass & 7 & 0 & 1 & 0 & 0 \\
\hline Ecosystem functioning \& population dynamics & 11 & 0 & 0 & 0 & 1 \\
\hline Ecosystem composition & 1 & 0 & 0 & 0 & 0 \\
\hline Unspecified & 5 & 0 & 0 & 0 & 0 \\
\hline Habitat quality & 1 & 0 & 0 & 0 & 0 \\
\hline Combination of metrics & 33 & 4 & 5 & 4 & 2 \\
\hline
\end{tabular}




\section{FIGURES}
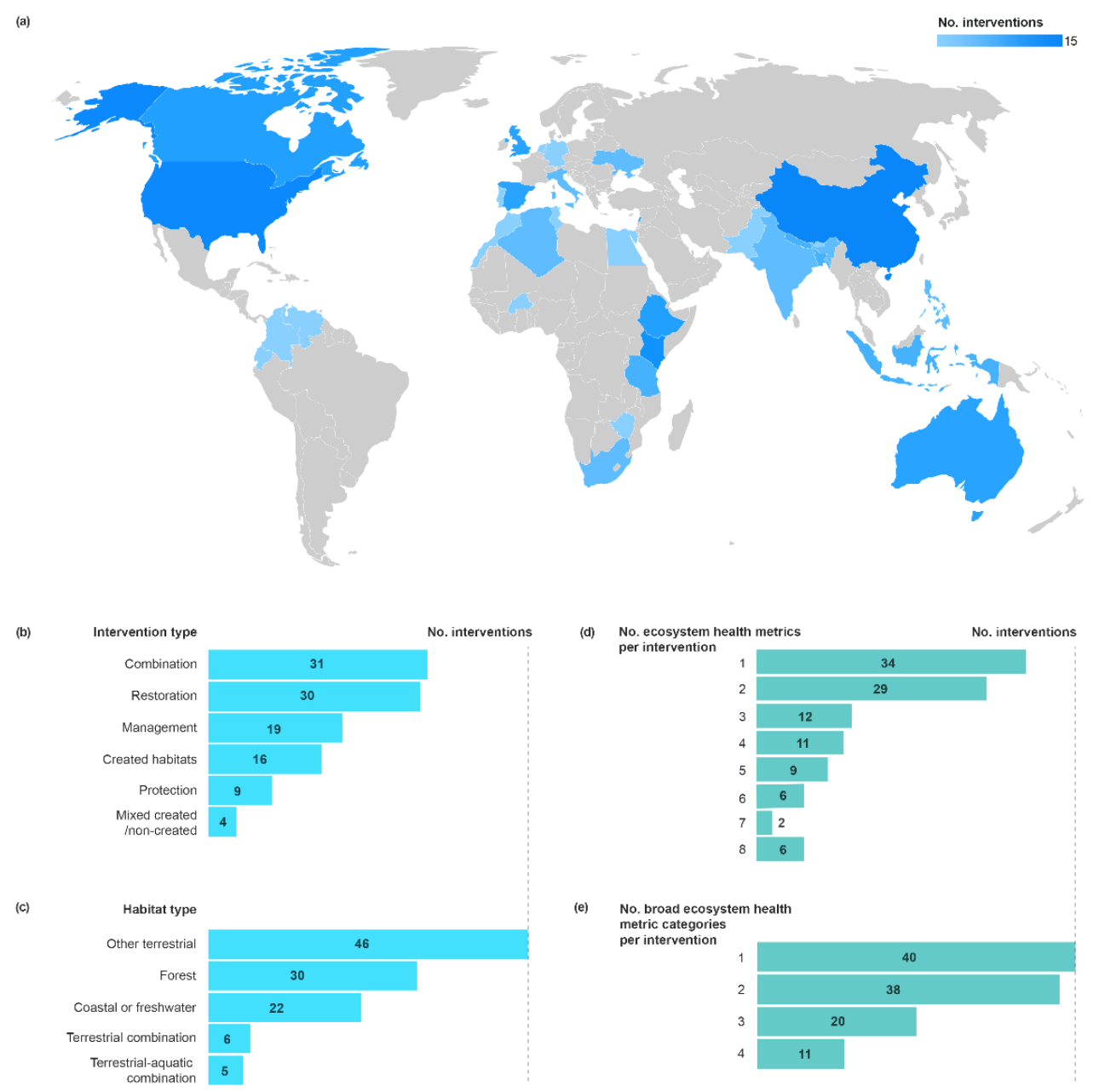

Figure 1: Global distribution of nature-based interventions identified in this study (a), number of interventions of each broad type of $\mathrm{NbS}$ (b), number of interventions in each habitat type (c), number of unique ecosystem health metrics per intervention (d), and number of unique broad ecosystem health metric categories per intervention (e). 


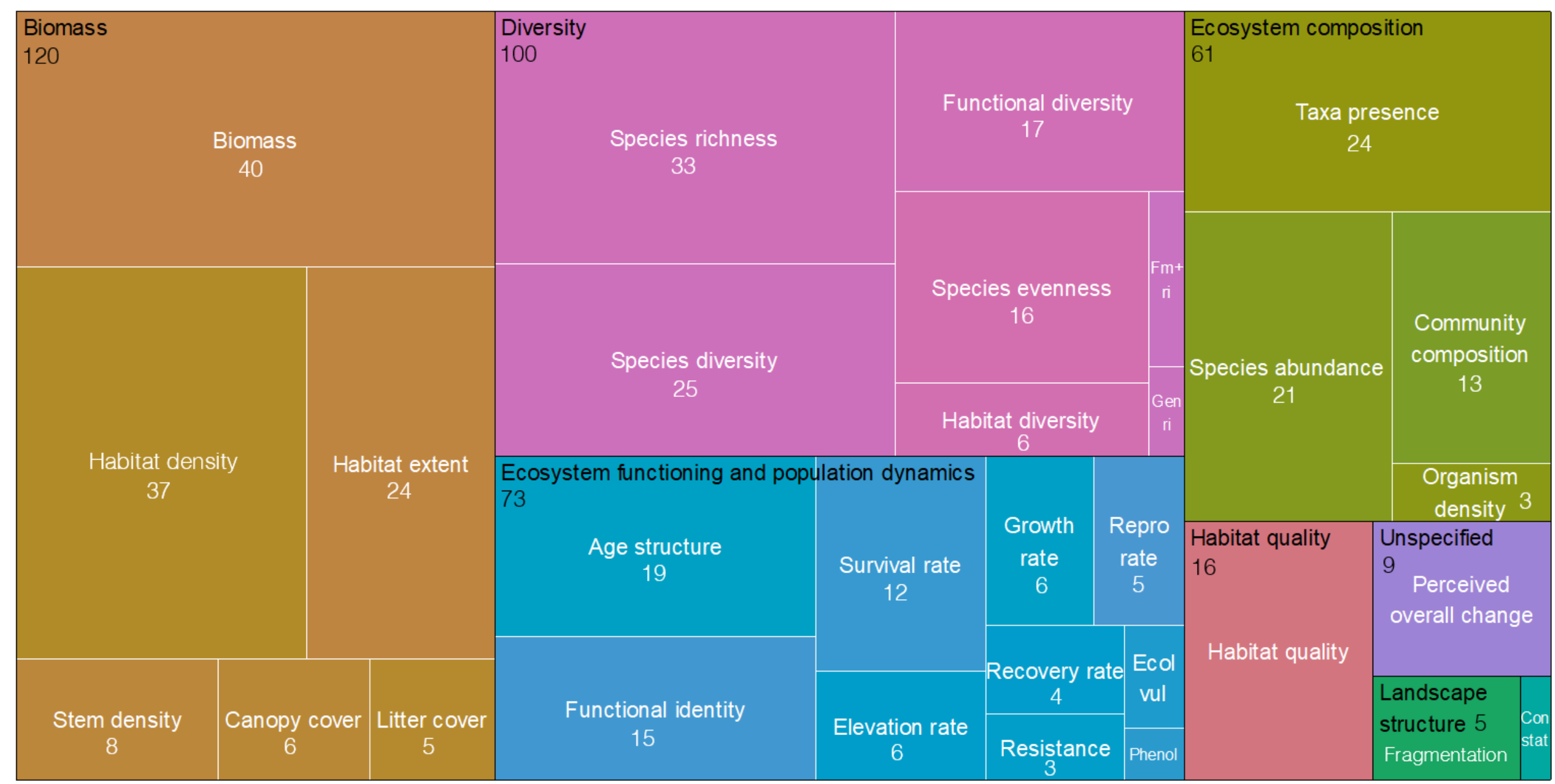

Figure 2: Frequency of use of ecosystem health metrics, grouped by broad metric categories. Box areas are proportional to frequency of use of ecosystem health metrics; metric names are in white; broad metric category names are in black; colours correspond to broad metric categories. 385 outcomes are represented here, across 109 interventions. Gen ri = generic richness; Fm+ ri = family and above richness; Repro rate = reproductive rate; Ecol vul = ecological vulnerability; Phenol = phenology; Con stat = conservation status. Two metrics that were defined a priori were not used at all by the studies: genetic diversity and phylogenetic diversity. For the number of interventions in each group, see Table S1. 


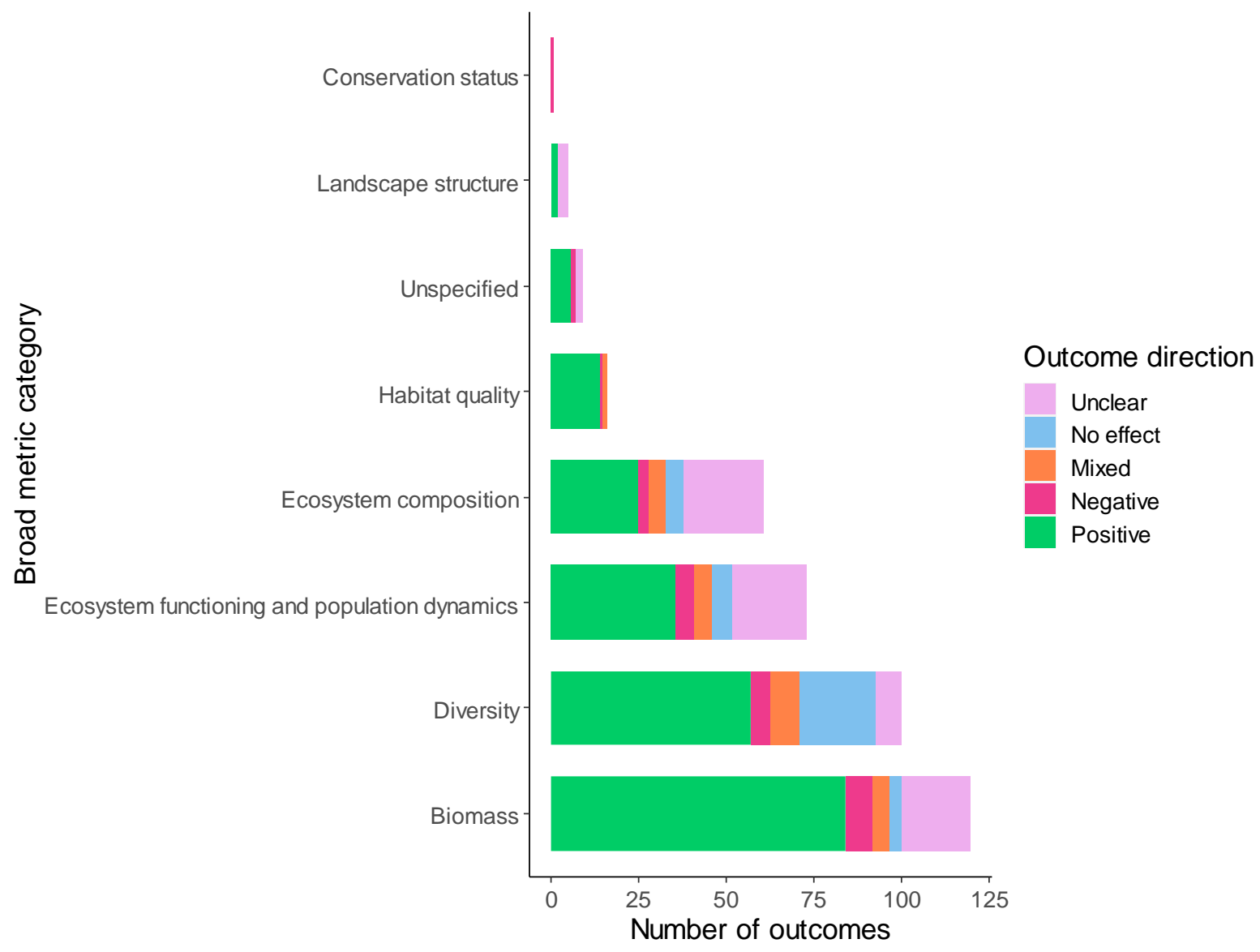

Figure 3: Outcomes for different broad categories of ecosystem health metrics. 


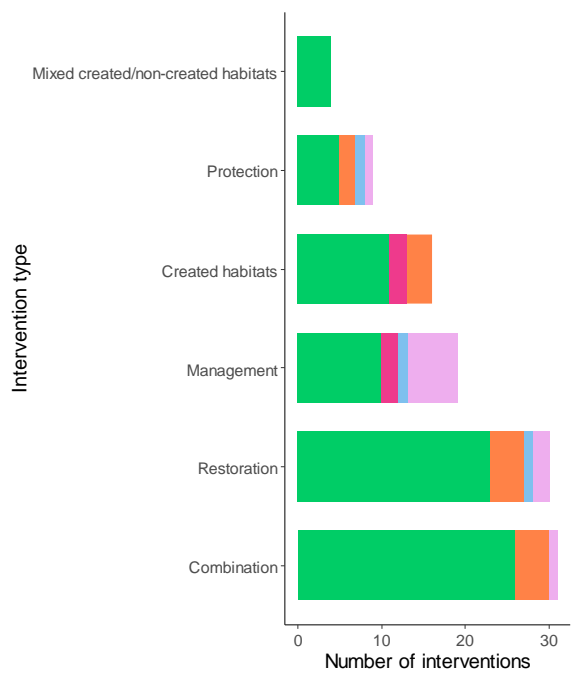

a

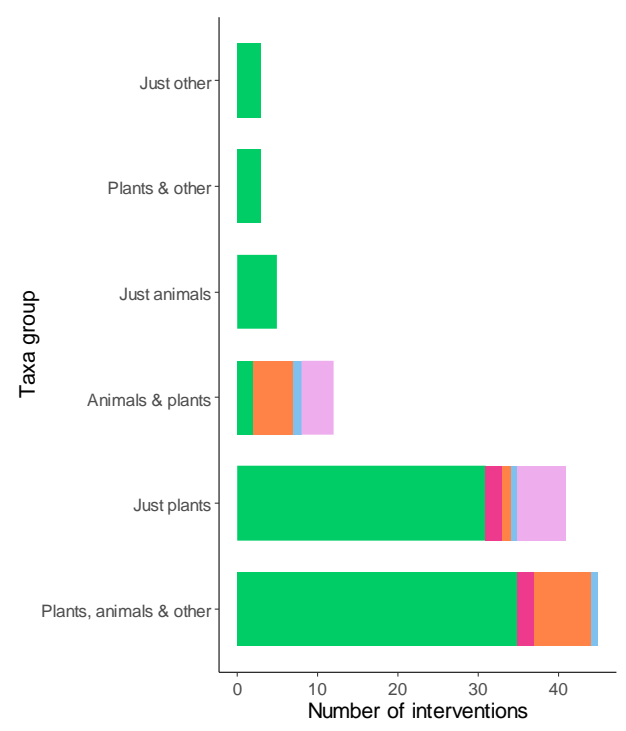

C
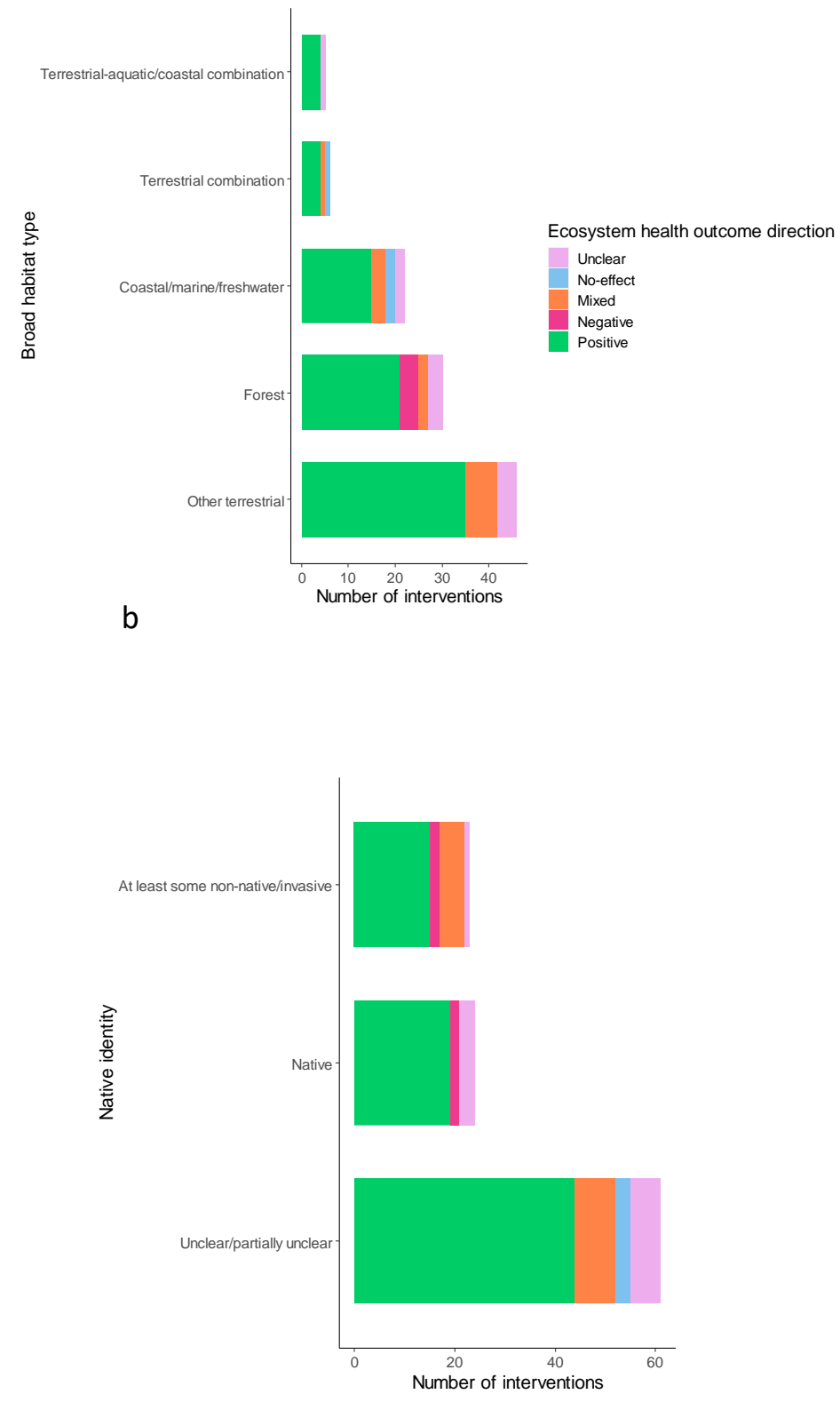

d

Figure 4: Ecosystem health outcomes of interventions split by intervention type (a), habitat type (b), taxonomic group (c), and native identity (d). 


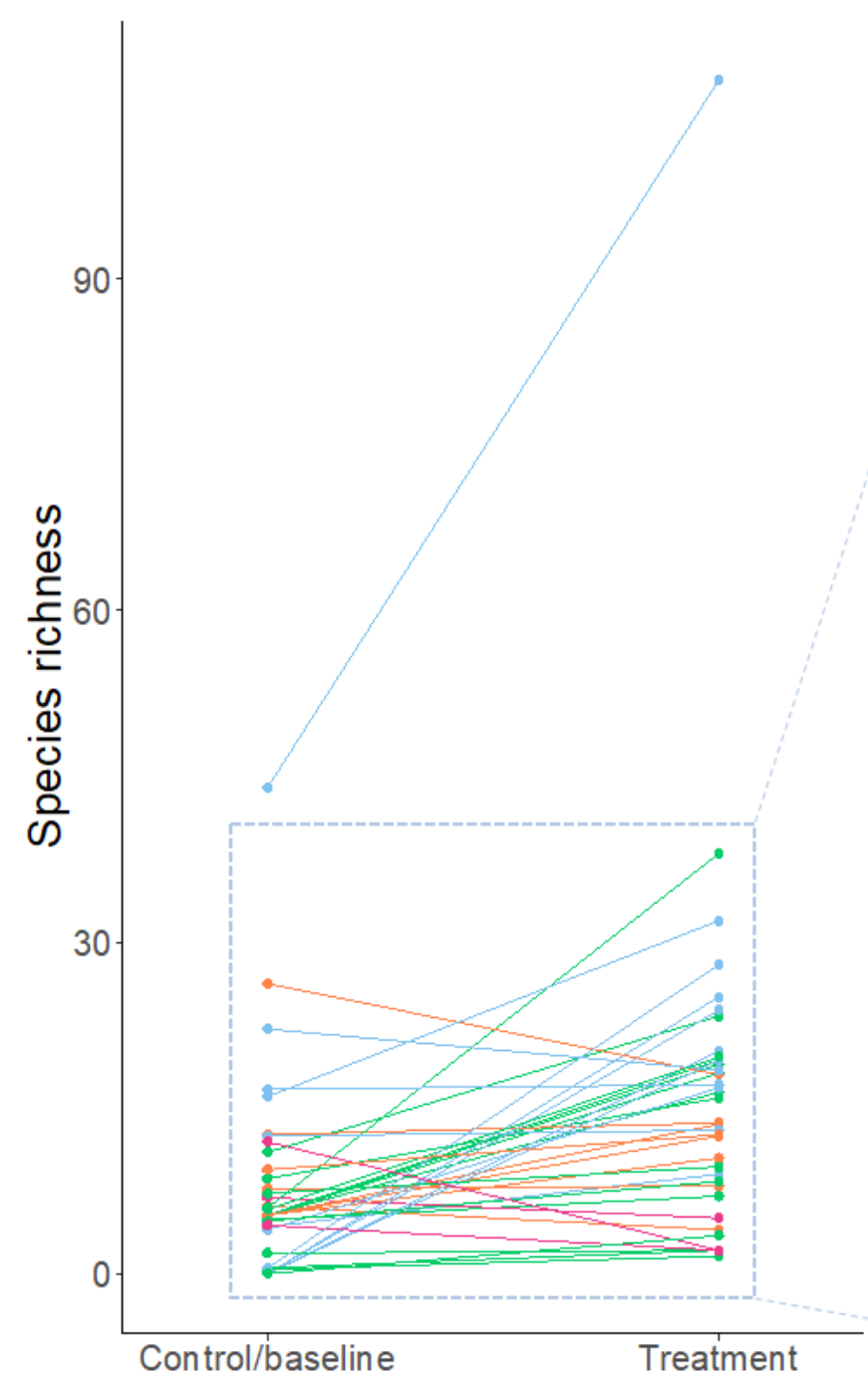

a

Figure 5: Change in species richness between control/baseline and treatment for 40 species richness outcomes, across 24 interventions. A larger scale view of the majority of the data from $8 \mathrm{a}$ is provided in $8 \mathrm{~b}$ for clarity. Green lines represent statistically significant positive changes, pink lines are significant negative changes, orange lines are non-significant changes, and blue lines are changes which were not statistically tested. The change in species richness from Biel et al. (2017) is not included in the figure because the number of species was not given, only percentage changes in species richness. 


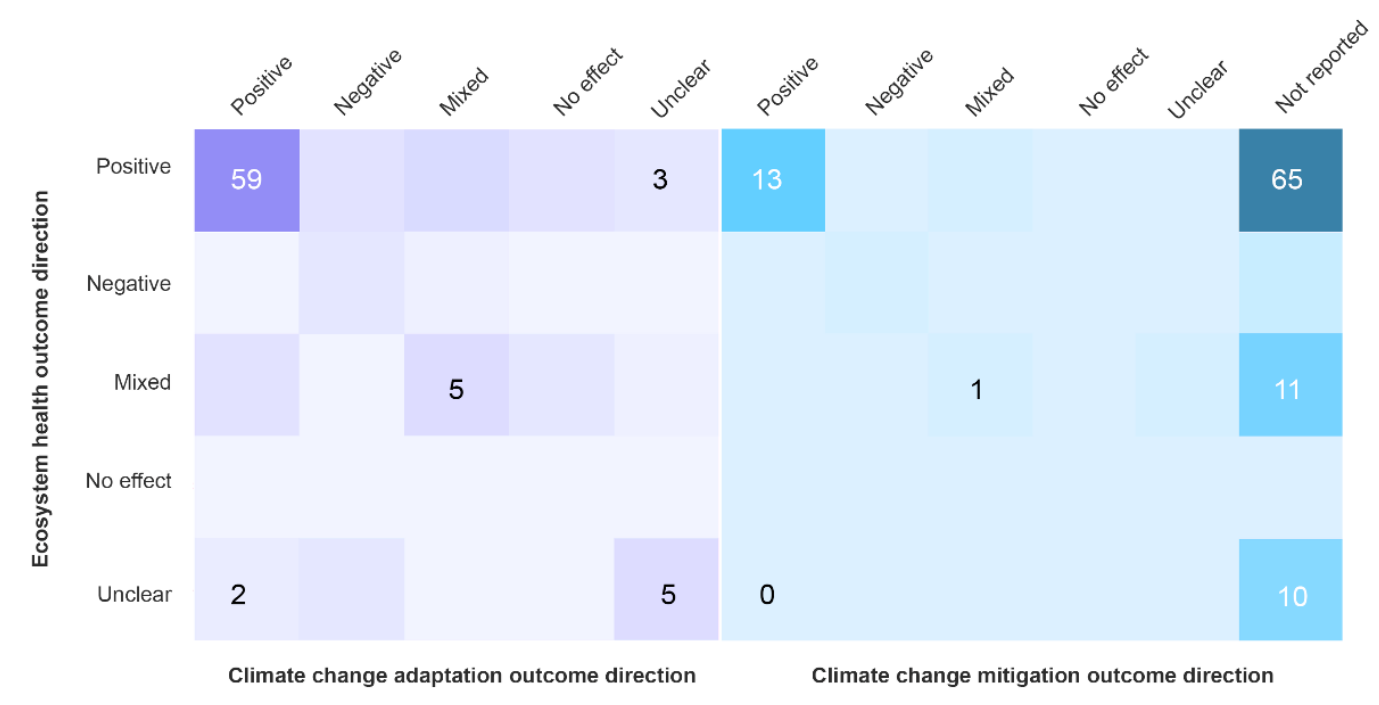

a

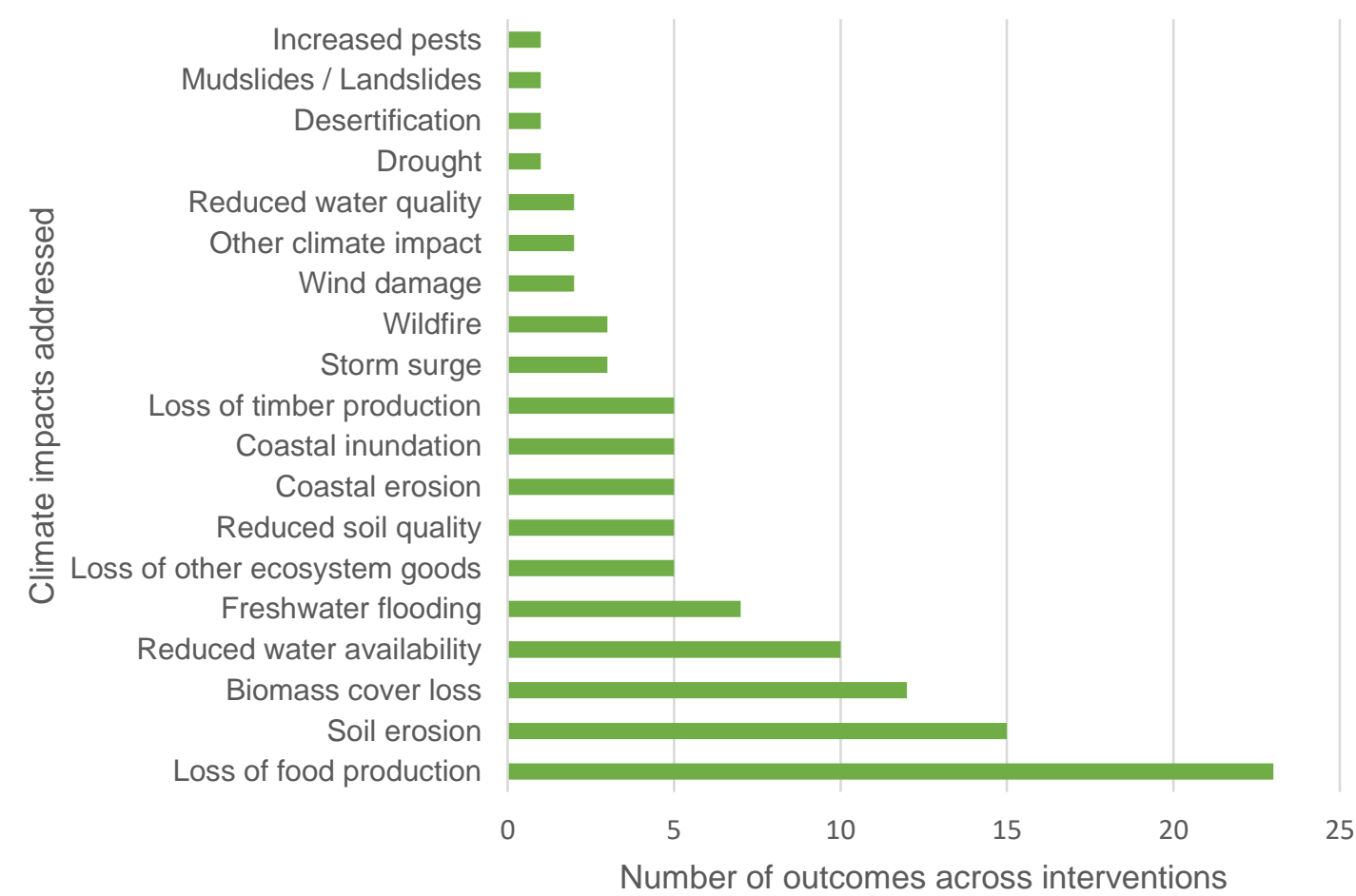

Figure 6: Associations between ecosystem health and climate change adaptation and mitigation outcomes across interventions (a); climate impacts addressed by interventions with positive outcomes for both ecosystem health and climate change adaptation (108 climate change adaptation outcomes across 79 interventions) (b). 